Article

\title{
Numerical Parametric Study of Countermeasures to Alleviate the Tunnel Excavation Effects on an Existing Tunnel in a Shallow-Buried Environment near a Slope
}

\author{
Ziyong $\mathrm{He}^{1,2}$, Chao $\mathrm{Li}^{1,2, *}$, Qiao $\mathrm{He}^{3}$, Yang Liu ${ }^{4,5}$ and Jiangong Chen ${ }^{1,2}$ \\ 1 School of Civil Engineering, Chongqing University, Chongqing 400045, China; he95082300@163.com (Z.H.); \\ cjg77928@126.com (J.C.) \\ 2 National Joint Engineering Research Center of Geohazards Prevention in the Reservoir Areas, \\ Chongqing 400045, China \\ 3 Powerchina Guiyang Engineering Corporation Limited, Guiyang 550081, China; qhegzdx@126.com \\ 4 State Key Laboratory of Geohazard Prevention and Geoenvironment Protection, Chengdu University of \\ Technology, Chengdu 610059, China; 18623120255@163.com \\ 5 Chongqing Survey Institute, Chongqing 401121, China \\ * Correspondence: 20151601010@cqu.edu.cn
}

Received: 5 December 2019; Accepted: 8 January 2020; Published: 15 January 2020

\begin{abstract}
This paper studies the influence law of existing tunnels on the construction of intersecting new tunnels in a shallow slope burial context through 3D numerical analysis. The emphasis is on exploring the effect of new tunnels constructed in 54 conditions, including three ratios of overburden to tunnel height $(\mathrm{C} / \mathrm{H})$, three ratios of slope distance to tunnel span $(\mathrm{D} / \mathrm{W})$, two backfilling conditions of the existing tunnel ("hty" and "htn" conditions), and three magnitudes of surface loads (10 kPa, 20 $\mathrm{kPa}$, and $30 \mathrm{kPa}$ ), on the deformation of lateral slopes and the overlying road. As the results show, the rigidly separated area between the existing and newly built tunnels in parallel to the excavation direction was precisely the sensitive area affected by the existing tunnel backfilling condition. The road settlement simulations perpendicular to the excavation direction revealed that various $\mathrm{C} / \mathrm{H}$ and $\mathrm{D} / \mathrm{W}$ ratio combinations controlled the shape and size differences of the settlement trough curve. This was because the $\mathrm{C} / \mathrm{H}$ ratio primarily controlled the effective span and height transition of the newly built tunnel, whereas the $\mathrm{D} / \mathrm{W}$ ratio mainly controlled the intersection position of the tunnels. Next, model A-A ("hty" condition) was identified as the only feasible construction model among all models in accordance with the engineering safety control criteria. Lastly, comparison of monitoring data with simulations found a slight difference in the distribution pattern between the two. Nevertheless, the final maximum settlement fully satisfied the construction control requirements overall. Aside from proving the correctness of simulation results, the present study also sets an excellent referential example for similar projects.
\end{abstract}

Keywords: shallow buried in the slope; tunnel interactions; ground settlement and slope deformation

\section{Introduction}

With the continuous progress of urbanization, the development and utilization of urban underground space resources have also been intensifying day by day. Among them, subway construction can relieve urban traffic congestion effectively, enabling more scientific and rational urban planning and reducing pollution, which helps to achieve green travel.

The interaction between subway tunnels and surface buildings was the main technical problem encountered in the construction of early urban subway projects. A series of studies have been carried out around this topic by many scholars [1,2]. As the urban population grows rapidly, the capacity of 
existing subways is no longer able to meet people's travel demands. As a result, the development and utilization of underground space resources have further intensified. Since the continued subway construction in the crowded urban space were only challenged in depth, the construction of subways at the present stage gives rise to another technical problem, namely the interaction between new and existing tunnels. In recent years, the interaction of overlapping tunnels in urban underground spaces has gradually become a hot research topic.

Shi et al. [3] analyzed the deformation mechanism of excavated caverns in the existing tunnels through numerical simulations. Their study took into consideration the effects of different tunnel depth/diameter ratios and circular cavern diameter/depth ratios, and verified the numerical model by utilizing centrifugal test results. In the past few years, they have explored the influences of factors like excavation geometry, excavation depth, ratio of overburden to tunnel diameter (depth/diameter ratio), and sand layer density on the tunnel invert excavation response based on the results of centrifuge tests via a numerical approach, and put forward a rather simple but practical evaluation method [4].

Yin et al. [5] investigated the soil stress variation and settlement evolution resulting from the orthogonal passing of a planned two-line earth pressure balance (EPB) shield tunnel underneath an existing tunnel and concluded that the shield exterior grouting in the construction process was effective in controlling the settlement. They also performed a parameter sensitivity analysis with Spearman's correlation coefficients, further finding that the elastic modulus of the filling material was a sensitive parameter affecting the settlement of existing tunnels and the ground surface.

In a study by Liang et al. [6], the influence caused by the oblique crossing of a newly built double-line tunnel above an existing tunnel was studied by simplifying the new tunnel into a continuous Euler-Bernoulli beam with a certain equivalent flexural stiffness. They also studied the effects of gap distance, propulsion distance, and multi-tunnel construction on the existing tunnels.

Deformation characteristics attributed to the oblique passing of a newly built twin tunnel underneath an existing tunnel were studied by Lin et al. [7] by focusing on discussing the variation trends of a ground settlement trough and the soil pressure acting on an existing tunnel during the shield tunneling. Then, they further derived the lateral deformation, internal force, and torsion characteristics of existing tunnels caused by a new tunnel excavation. Finally, they explored the influence of the skew angle variation of spatially overlapping tunnels on the deformation of existing tunnels and found that the skew angle was significantly influential on the maximum settlement of the existing tunnel floor, but was only a little influential on the maximum settlement of the existing tunnel roof.

Employing PLAXS software numerical analysis, Vinod and Khabbaz [8] studied the surface settlements and bending moments of circular and rectangular twin tunnel linings, where the key research parameters included the relative position, critical distance, volume loss, overburden, and size of the twin tunnel.

$\mathrm{Ng}$ et al. [9] investigated the interaction between the breadth of an existing horseshoe tunnel and diameter of a new circular tunnel (B/D) at the time of vertical passing. As the computational results reveal, the maximum settlement of the existing tunnel's invert center was unaffected by the magnitude of the B/D ratio at different overburden depths. At smaller overburden depths, however, the settlement profile of the existing tunnel's roof became gradually arched with the increasing B/D ratio.

To sum up, the studies on spatially overlapping tunnels remain concentrated on the effects of tunnel excavation on the ground surface [7,10-13], on the existing buildings [3,4], and on the existing tunnels $[5,6,14-16]$. In particular, the studies cover the interactions between the following four systems: spatial arrangement between tunnels, tunnel geometric parameters, key technical parameters of tunnel construction, and engineering geological conditions. The tunnel passing modes have changed from vertical passing to oblique passing $[16,17]$, and the tunnel geometry has also been gradually transformed from circular shapes [18] to non-circular shapes [19,20].

However, it is not difficult to find through a literature review that the spatially overlapping tunnels intersect only in terms of a spatial angle in terms of the geometrical position, while the tunnels on the same geometric plane do not intersect [8]. In China's Yunnan-Guizhou Plateau, a type of tunnel 
with a peculiar location, i.e., shallow buried slope adjacent tunnels, are introduced for mountainous cities for topographic and geomorphologic reasons. These tunnels are adjacent to the slopes and the ground's surface. According to a review of the literature, the previous studies focused mainly on the interaction problem of a new tunnel excavation passing transversely through, underneath, or above the existing tunnel, or passing vertically underneath the existing tunnel. In contrast, the shallow buried slope adjacent tunnels are scarcely studied, especially regarding the impact on the construction of a shallow buried slope adjacent intersecting tunnels, which remains to be understood further.

The new tunnel in the project studied herein lies beneath the running road. To better understand the impact of shallow slope adjacent tunnel construction on the road and slope stability, this study adopted the systematic numerical analysis of parameters to explore the effects of a new tunnel on the road and slopes under various factors, including nine spatial locations (three overburdens and three slope distances), three magnitudes of surface loads, and two backfilling conditions of the existing tunnel. The findings of this paper provide a relatively fast, low-cost, and safe solution prior to construction, thus enabling engineers to have a reference for assessing the impacts and risks of tunneling in the preliminary design phase.

\section{Engineering Geological Conditions}

Qingshuihe Tunnel is located in Panlong Village, Liupanshui, Guizhou Province. The new tunnel, which will pass underneath the Shuihuang Highway, will have an entrance grade elevation of 1175.325 $\mathrm{m}$, an exit grade elevation of $1177.805 \mathrm{~m}$, and a length of $100 \mathrm{~m}$.

\subsection{Topography, Geomorphology, and Regional Tectonics}

The tunnel site is a tectonically denuded middle mountainous area. The overall terrain is low in the south and high in the north. The highest northern point is at the top of the mountain, while the southern slope toe is a residential area road, as shown in Figure 1. The slope toe is excavated to form a high slope that is approximately $40 \mathrm{~m}$ in height. With an average slope angle of about $82^{\circ}$, the slope is rather steep. The tunnel is located inside the slope, whose orientation is nearly parallel to that of the slope.

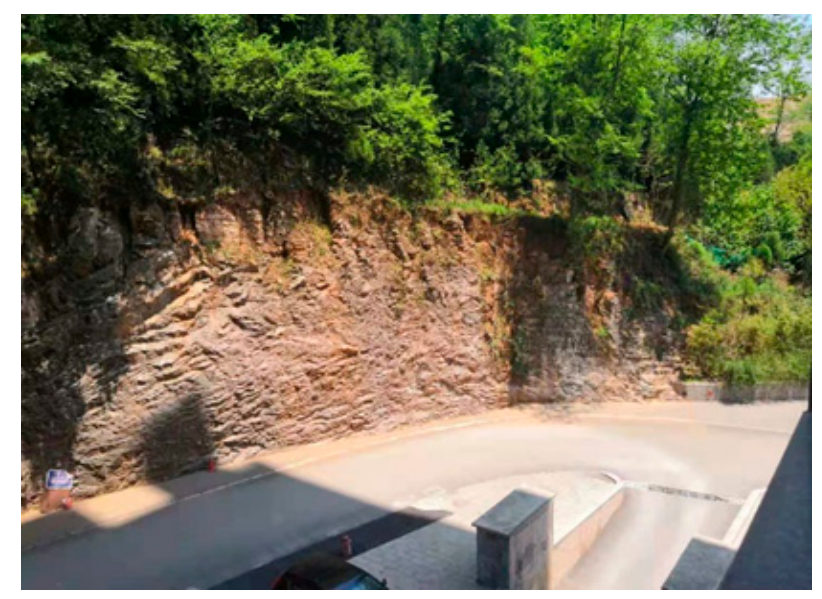

Figure 1. Photo of the slope toe.

Given the early formation of the fault structure in the tunnel site, it has been basically stable, without any data indicating traces of its activity so far. Thus, it produces no impact on the stability of tunnel route. In the middle mountain region where the project is located, no fault structure distribution was found, and the geologic agents are mainly tectonic erosion and denudation, with weak neotectonic activity. To sum up, there is no fault crossing the tunnel route near the exploration area, and the age of the fault structure is rather old, and has been fundamentally stable without active development. The region has an overall good geological stability, showing no structural traces that subvert the route. 


\subsection{Stratum Lithology}

\subsubsection{Eluvial Layer $\left(\mathrm{Q}_{4}{ }^{\mathrm{e}+\mathrm{dl}}\right)$}

The tunnel is adjacent to the slope zone on the south of the mountain, which is dominated by silty clay containing aggregate and rubble. The silty clay is yellow or purple in color, which is plastic to rigidly plastic, with a medium dry strength and toughness. It contains moderately to intensely weathered limestone, gravels, aggregate, and rubble. The gravel and rubble are generally 1-600 $\mathrm{mm}$ in diameter, angular in shape, arranged disorderly and distributed unevenly, with contents ranging between $10-30 \%$ and locally reaching $40 \%$. According to a field investigation, the thickness of the stratum was $0.5-1.2 \mathrm{~m}$ in general.

\subsubsection{Lower Permian Qixia Formation $\left(P_{1} q\right)$}

The lithology is limestone that is dark gray or gray in color. The main mineral components are carbonates like calcite showing cementation, a medium-thick layered structure, and a cryptocrystalline texture. Small-scale strongly weathered rock masses can be seen in the cavern opening section, which are fragmented, as shown in Figure 2a. In contrast, the moderately weathered rock masses of the trunk section are rather intact and mostly in a medium-thick layered structure, as shown in Figure $2 \mathrm{~b}$. The stratum inclination is $60^{\circ}-80^{\circ}$, and the strike of the tunnel central axis is $72^{\circ}$, two of which are nearly consistent in terms of strike. Strata with dips of $62^{\circ}-78^{\circ}$ are defined as steeply dipping strata.

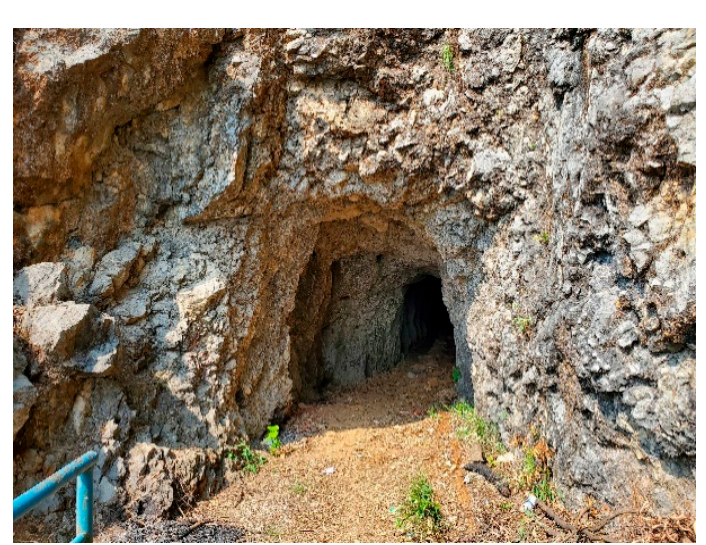

(a)

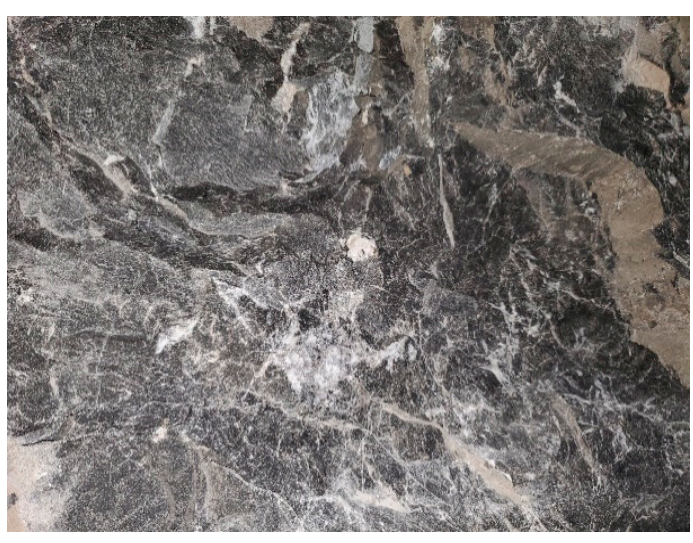

(b)

Figure 2. Photos of the surrounding rocks in the entrance and trunk sections: (a) surrounding rocks at the portal and (b) surrounding rocks in the trunk section.

\subsection{Hydrogeological Conditions}

The planned tunneling site passes through the limestone stratum in the Lower Permian Qixia Formation. As the field investigation revealed, the underground water in the tunneling area is mainly carbonate karst fissure water, according to the lithology and water-bearing characteristics of the aquifer (layer) group. The main manifestations of karst are dissolution pores and cracks. According to the in situ exploration and drilling, the dissolution pores and cracks of rock core are generally $1-6 \mathrm{~cm}$ in size, precipitation of calcite crystals is present, and the karst caves are not exposed. Investigation of the ground surface and tunnel exit cliffs found no development of karst caves, as shown in Figure 3a. 


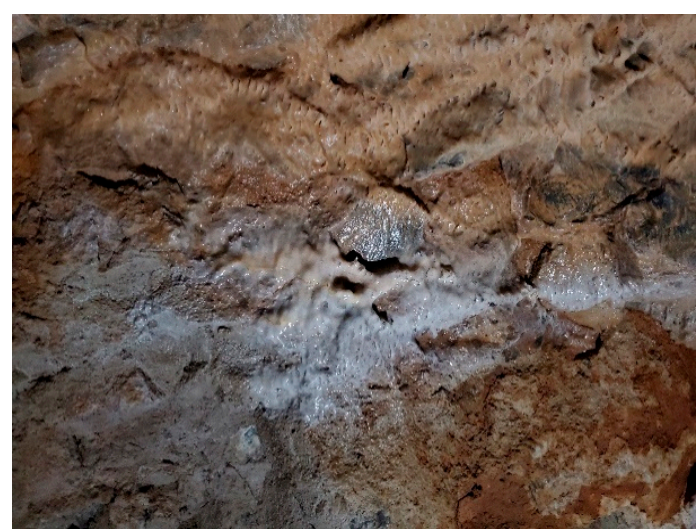

(a)

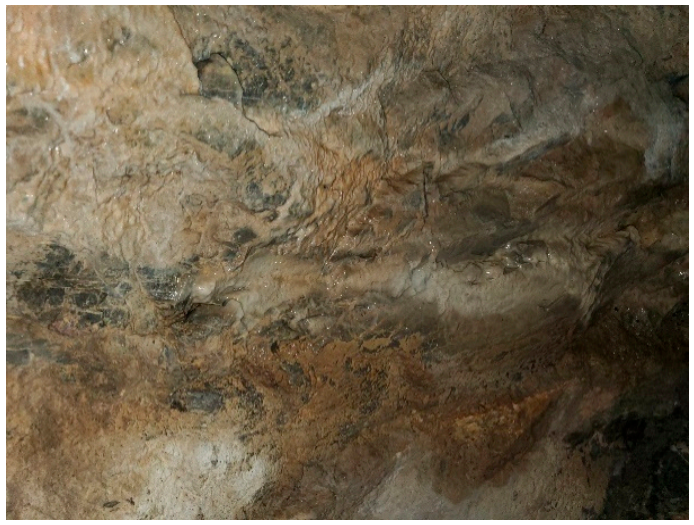

(b)

Figure 3. Cavern karst phenomena: (a) calcium crystal precipitation and (b) cavern wall dripping.

The new tunnel is constructed nearly parallel to the slope orientation. The bottom elevation of the tunnel is higher than the groundwater level, and its overburden is shallow. Its top is a mountain slope zone, which is beneficial for ground surface drainage. The surface drainage is mostly discharged through overland runoff, while only a small part is infiltrated to replenish the groundwater. High-to-low migration is achieved via karst fissures and conduits. An in situ investigation of the existing tunnels showed that the dampening and dripping of local cavern walls are seen occasionally, as shown in Figure $3 \mathrm{~b}$. Hence, the possibility of water inrush in the tunnel is small, and there is no major spring resource near the exploration area.

According to the water sample test results of the groundwater and environmental water, regional hydrogeological data, and local experience in Liupanshui, the groundwater, environmental water, and soil layers in the tunnel site are slightly corrosive to concrete structure. In the present exploration, no groundwater was found in the two boreholes, and one surface water sample was collected for the laboratory analysis of water quality. As the results show, the surface water was slightly corrosive to both the concrete structure and rebar.

\section{Rock Engineering Characteristics and Rock Mass Classification}

\subsection{Geotechnical, Physical, and Mechanical Properties}

The natural weight, saturated, and natural uniaxial compressive test results of limestone stratum in the present exploration were subjected to mathematical statistical processing in accordance with relevant specifications. Table 1 lists the statistical results.

\subsection{Basic Quality (BQ) Classification of the Rocks Surrounding the Tunnel}

A surrounding rock classification for the explored tunnel was implemented in accordance with relevant regulations in the Chinese Specifications for Design of Highway Tunnels (JTG C20-2011).

Initially, a rock hardness classification was carried out depending on the mechanical properties of different rocks in the tunnel site, and the $B Q$ value was calculated according to the rock mass integrity coefficient $K v$ determined using borehole acoustic logging and the development degree of rock mass fractures. Meanwhile, the surrounding rocks were preliminarily graded. Afterward, the detailed grading of surrounding rocks was carried out depending on the tunnel overburden and the criticality of groundwater to surrounding rocks by taking into account the influence of the surrounding rock's geological structure, the development degree of the surrounding rock joints, and the impact of weathering characteristics of various surrounding rocks on their strength. The rocks surrounding the tunnel were classified into five types according to the standard value $R c$ for a saturated rock's compressive strength in the tunnel site as follows: extremely soft rock, soft rock, slightly soft 
rock, slightly hard rock, and hard rock. Field sampling and laboratory tests of rock masses from the exploration area revealed that the saturated compressive strength of limestone in the tunnel site was 35.6 MPa, which is classified as slightly hard.

Table 1. Geotechnical, physical, and mechanical properties.

\begin{tabular}{|c|c|c|c|c|c|}
\hline \multirow{2}{*}{ Stratum } & \multirow{2}{*}{ Lithology } & \multirow{2}{*}{$\begin{array}{l}\text { Rock Sample } \\
\text { No. }\end{array}$} & \multirow{2}{*}{$\begin{array}{c}\text { Physical Property } \\
\text { Natural Weight }\left(\mathrm{kg} \cdot \mathrm{m}^{-3}\right)\end{array}$} & \multicolumn{2}{|c|}{ Rock Uniaxial Compressive Strength } \\
\hline & & & & Natural (MPa) & Saturated (MPa) \\
\hline \multirow{9}{*}{$\mathrm{P}_{1} \mathrm{q}$} & \multirow{9}{*}{ Limestone } & \multirow{3}{*}{ ZY01 } & 2657 & 39.7 & 34.2 \\
\hline & & & 2645 & 40.2 & 35.1 \\
\hline & & & 2641 & 43.6 & 38.2 \\
\hline & & \multirow{3}{*}{ ZY02 } & 2664 & 41.5 & 35.2 \\
\hline & & & 2663 & 40.2 & 34.9 \\
\hline & & & 2655 & 45.9 & 40.8 \\
\hline & & \multirow{3}{*}{ ZY02-1 } & 2628 & 45.2 & 38.5 \\
\hline & & & 2626 & 43.6 & 37.0 \\
\hline & & & 2627 & 47.9 & 40.7 \\
\hline \multicolumn{3}{|c|}{ Average } & 2645 & 43.09 & 37.18 \\
\hline \multicolumn{3}{|c|}{ Minimum } & 2628 & 39.70 & 34.20 \\
\hline \multicolumn{3}{|c|}{ Maximum } & 2664 & 47.90 & 40.8 \\
\hline \multicolumn{3}{|c|}{ Softening coefficient } & & \multicolumn{2}{|r|}{0.86} \\
\hline \multicolumn{3}{|c|}{ Standard deviation } & & 2.888 & 2.516 \\
\hline \multicolumn{3}{|c|}{ Coefficient of variation } & & 0.067 & 0.068 \\
\hline \multicolumn{3}{|c|}{ Standard value } & & 41.28 & 35.60 \\
\hline
\end{tabular}

By consulting Clause 3.6.3 of the Specifications for Design of Highway Tunnels (JTG C20-2011) and Clause 4.2.2 of the Standards for Engineering Classification of Rock Masses (GB/T 50218-2014), the computational formula was derived as:

$$
B Q=90+3 R c+250 K v,
$$

where $R c=90 \mathrm{Kv}+30$ if $R c>90 \mathrm{Kv}+30$; and $K v=0.04 R c+0.4$ if $K v>0.04 R c+0.4$.

In the case of complicated rock engineering conditions, correcting the results of a primary rock mass quality classification is necessary. The correction of rock mass classification in the studied project primarily involved the groundwater effect correction coefficient $K_{1}$. Table 2 lists the correction results. There was no weak structural plane in the moderately weathered stratum of the tunnel site, nor the presence of high geostress. The effect correction coefficient $K_{2}$ for main weak structural plane occurrence was set to be 0 , and the effect correction coefficient $K_{3}$ for initial stress state was also set to be 0 . In Table 3, the final correction results of the surrounding rock classification are presented.

Table 2. Groundwater effect correction factor $K_{1}$.

\begin{tabular}{|c|c|c|c|c|}
\hline Section No. & Mileage Pile No. & $\begin{array}{l}\text { Basic Quality } \\
\text { Index } B Q\end{array}$ & Groundwater Effluent Status & $\begin{array}{c}\text { Effect Correction } \\
\text { Coefficient } K_{1}\end{array}$ \\
\hline (1) & K0+000-K0+018 (18) & & & \\
\hline (2) & K0+018-K0+023 (6) & 349.5 & $\begin{array}{l}\text { This section was located in the karst fissure } \\
\text { zone developed along the rock stratum. Water } \\
\text { seepage was found during the investigation. In } \\
\text { the rainy season, the groundwater is } \\
\text { discharged in drips. }\end{array}$ & 0.2 \\
\hline (3) & K0+023-K0+88 (65) & 366.8 & $\begin{array}{l}\text { The surrounding rocks in this section are } \\
\text { moderately weathered limestone, where there } \\
\text { is scarce groundwater. Local dampening was } \\
\text { observed during the investigation. }\end{array}$ & 0.1 \\
\hline (4) & K0+88-K0+100 (12) & & & \\
\hline
\end{tabular}


Table 3. Final surrounding rock classification results for the new tunnel.

\begin{tabular}{|c|c|c|c|c|c|c|c|c|c|c|c|c|c|c|c|c|c|c|c|}
\hline \multirow{3}{*}{$\begin{array}{l}\text { Section } \\
\text { No. }\end{array}$} & \multirow{3}{*}{$\begin{array}{l}\text { Mileage } \\
\text { Pile No. } \\
\end{array}$} & \multicolumn{4}{|c|}{ Rock Hardness Classification } & \multicolumn{4}{|c|}{ Rock Integrity Classification } & \multicolumn{10}{|c|}{ Rock Grade Classification } \\
\hline & & \multirow{2}{*}{$\begin{array}{l}\text { Passing } \\
\text { Stratum }\end{array}$} & \multirow{2}{*}{$\begin{array}{l}\text { Main } \\
\text { Lithology } \\
\text { Affecting } \\
\text { Surroundin } \\
\text { Rocks }\end{array}$} & \multirow{2}{*}{$\begin{array}{l}\text { Standard Value of } \\
\text { Saturated } \\
\text { Compressive } \\
\mathrm{g} \text { Strength (MPa) }\end{array}$} & \multirow[t]{2}{*}{ Hardness } & \multirow{2}{*}{$\begin{array}{l}\text { Volume } \\
\text { Joint } \\
\text { Number } \\
\text { Jv } \\
\text { (Fissures/ } / \mathrm{m}^{3} \text { ) }\end{array}$} & \multirow{2}{*}{$\begin{array}{l}\text { Rock Integrity } \\
\text { Coefficient } K v\end{array}$} & \multirow{2}{*}{$\begin{array}{l}\text { Qualitative } \\
\text { Indices }\end{array}$} & \multirow[t]{2}{*}{ Integrity } & \multicolumn{2}{|c|}{ Qualitative Classification } & \multicolumn{2}{|c|}{$\begin{array}{c}\text { Preliminary Quantitative } \\
\text { Classification }\end{array}$} & \multicolumn{5}{|c|}{ Detailed Quantitative Classification } & \multirow{2}{*}{$\begin{array}{c}\begin{array}{c}\text { Comprehensive } \\
\text { Classification }\end{array} \\
\begin{array}{c}\text { Final } \\
\text { Surrounding } \\
\text { Rock Grade }\end{array}\end{array}$} \\
\hline & & & & & & & & & & $\begin{array}{c}\text { Main Qualitative } \\
\text { Characteristics of } \\
\text { Surrounding Rocks } \\
\text { or Soils }\end{array}$ & $\begin{array}{l}\text { Surrounding } \\
\text { Rock Grade }\end{array}$ & $\begin{array}{c}\text { Basic Quality } \\
\text { Index of } \\
\text { Surrounding } \\
\text { Rocks } B Q\end{array}$ & $\begin{array}{l}\text { Surrounding } \\
\text { Rock Grade }\end{array}$ & $K_{1}$ & $\mathrm{~K}_{2}$ & $K_{3}$ & $\begin{array}{c}\text { Modified } \\
\text { Basic Quality } \\
\text { Index of } \\
\text { Surrounding } \\
\text { Rocks BQ }\end{array}$ & $\begin{array}{l}\text { Surrounding } \\
\text { Rock Grade }\end{array}$ & \\
\hline (1) & $\begin{array}{c}\mathrm{K} 0+000-\mathrm{K} 0+01 \\
(18)\end{array}$ & $\begin{array}{l}+018 \\
\quad P_{1} q\end{array}$ & $\begin{array}{l}\text { Strongly } \\
\text { weathered } \\
\text { limestone }\end{array}$ & & $\begin{array}{l}\text { Slightly } \\
\text { soff rocks }\end{array}$ & & & $\begin{array}{l}\text { Rock cores } \\
\text { were mostly } \\
\text { fragmental or } \\
\text { short } \\
\text { columnar; } \\
\text { development } \\
\text { of weathered } \\
\text { fissures was } \\
\text { seen. }\end{array}$ & $\begin{array}{c}\text { Rather } \\
\text { fractured }\end{array}$ & 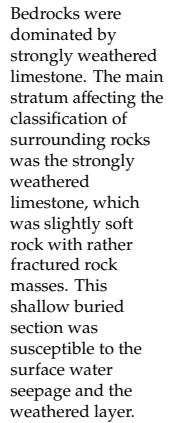 & IV & & IV & & & & & IV & IV \\
\hline (2) & $\begin{array}{c}\mathrm{K} 0+018-\mathrm{K} 0+02 \\
(5)\end{array}$ & & $\begin{array}{l}\text { Slightly } \\
\text { to } \\
\text { moderately } \\
\text { weathered } \\
\text { limestone }\end{array}$ & 35.6 & $\begin{array}{l}\text { Slightly } \\
\text { hard } \\
\text { rocks }\end{array}$ & $7-10$ & 0.60 & 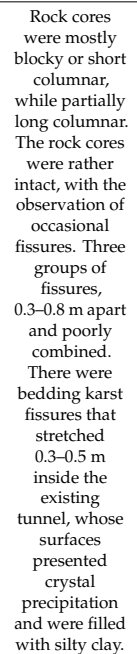 & Rather intact & 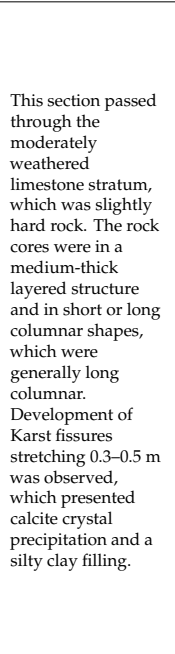 & IV & & IV & 0.2 & 0 & 0 & 329.5 & IV & IV \\
\hline
\end{tabular}


Table 3. Cont.

\begin{tabular}{|c|c|c|c|c|c|c|c|c|c|c|c|c|c|c|c|c|c|c|c|}
\hline \multirow{3}{*}{$\begin{array}{l}\text { Section } \\
\text { No. }\end{array}$} & \multirow{3}{*}{$\begin{array}{l}\text { Mileage } \\
\text { Pile No. }\end{array}$} & \multicolumn{4}{|c|}{$\begin{array}{l}\text { Rock Hardness Classification } \\
\end{array}$} & \multicolumn{4}{|c|}{ Rock Integrity Classification } & \multicolumn{10}{|c|}{ Rock Grade Classification } \\
\hline & & \multirow{2}{*}{$\begin{array}{l}\text { Passing } \\
\text { Stratum }\end{array}$} & \multirow{2}{*}{$\begin{array}{l}\text { Main } \\
\text { Lithology } \\
\text { Affecting } \\
\text { Surroundin } \\
\text { Rocks }\end{array}$} & \multirow{2}{*}{$\begin{array}{c}\text { Standard Value of } \\
\text { Saturated } \\
\text { Compressive } \\
\text { gtrength (MPa) }\end{array}$} & \multirow[t]{2}{*}{ Hardness } & \multirow{2}{*}{$\begin{array}{l}\text { Volume } \\
\text { Joint } \\
\text { Number } \\
\text { Jv } \\
\text { (Fissures/m3) } \\
\end{array}$} & \multirow{2}{*}{$\begin{array}{l}\text { Rock Integrity } \\
\text { Coefficient } K v\end{array}$} & \multirow{2}{*}{$\begin{array}{l}\text { Qualitative } \\
\text { Indices }\end{array}$} & \multirow[t]{2}{*}{ Integrity } & \multicolumn{2}{|c|}{ Qualitative Classification } & \multicolumn{2}{|c|}{$\begin{array}{l}\text { Preliminary Quantitative } \\
\text { Classification }\end{array}$} & \multicolumn{5}{|c|}{ Detailed Quantitative Classification } & \multirow{2}{*}{$\begin{array}{c}\begin{array}{c}\text { Comprehensive } \\
\text { Classification }\end{array} \\
\text { Final } \\
\text { Surrounding } \\
\text { Rock Grade }\end{array}$} \\
\hline & & & & & & & & & & $\begin{array}{c}\text { Main Qualitative } \\
\text { Characteristics of } \\
\text { Surrounding Rocks } \\
\text { or Soils }\end{array}$ & $\begin{array}{l}\text { Surrounding } \\
\text { Rock Grade }\end{array}$ & $\begin{array}{l}\text { Basic Quality } \\
\text { Index of } \\
\text { Surrounding } \\
\text { Rocks } B Q\end{array}$ & $\begin{array}{l}\text { Surrounding } \\
\text { Rock Grade }\end{array}$ & $K_{1}$ & $K_{2}$ & $K_{3}$ & $\begin{array}{l}\text { Modified } \\
\text { Basic uality } \\
\text { Index of } \\
\text { Surrounding } \\
\text { Rocks } B Q\end{array}$ & $\begin{array}{l}\text { Surrounding } \\
\text { Rock Grade }\end{array}$ & \\
\hline (3) & $\underset{(65)}{\mathrm{K} 0+023-\mathrm{K} 0+8}$ & & & 35.6 & $\begin{array}{l}\text { Slightly } \\
\text { hard } \\
\text { rocks }\end{array}$ & $3 \sim 7$ & 0.65 & $\begin{array}{l}\text { Rock cores } \\
\text { were short to } \\
\text { long columnar } \\
\text { shaped, with a } \\
\text { small number } \\
\text { of blocky to } \\
\text { short } \\
\text { columnar ones. } \\
\text { Fissures were } \\
\text { seen } \\
\text { occasionally in } \\
\text { the rock cores. } \\
\text { Three groups } \\
\text { of fissures, } \\
0.5-1.0 \mathrm{~m} \\
\text { apart and } \\
\text { moderately } \\
\text { combined. } \\
\end{array}$ & $\begin{array}{c}\text { Rather/completel } \\
\text { intact }\end{array}$ & $\begin{array}{l}\text { This section passed } \\
\text { throught the } \\
\text { moderately } \\
\text { weathered } \\
\text { limestone stratum, } \\
\text { which was slightly } \\
\text { lyard rock. The rock } \\
\text { cores were in a } \\
\text { medium-thick } \\
\text { layered structure } \\
\text { and in short or long } \\
\text { columnar hhapes, } \\
\text { which were } \\
\text { generally long } \\
\text { columnar. }\end{array}$ & III & 366.8 & III & 0.1 & 0 & 0 & 356.8 & III & III \\
\hline (4) & $\frac{{ }_{(12)}^{\mathrm{K} 0+88-\mathrm{K} 0+10}}{}$ & & & 35.6 & $\begin{array}{l}\text { Slightly } \\
\text { hard } \\
\text { rocks }\end{array}$ & $11-15$ & 0.48 & $\begin{array}{c}\text { Rock cores } \\
\text { were mostly } \\
\text { fragmental or } \\
\text { short } \\
\text { columnar; } \\
\text { development } \\
\text { of weathered } \\
\text { fissures was } \\
\text { seen. }\end{array}$ & $\begin{array}{l}\text { Rather } \\
\text { fractured }\end{array}$ & 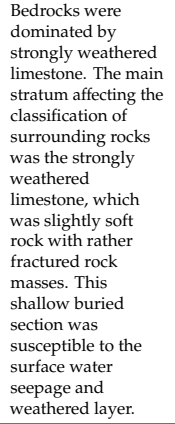 & IV & & IV & & & & & IV & IV \\
\hline
\end{tabular}




\section{Numerical Model and Construction Plan}

There is a pedestrian passage that was manually excavated in the 1980s in the planned tunnel site. The bedrock is bare, with a sectional size of $1.5 \mathrm{~m}$ (width) $\times 2.2 \mathrm{~m}$ (height). A new horseshoe tunnel with a length of $100 \mathrm{~m}$ and a sectional size of $5.88 \mathrm{~m}$ (width) $\times 6.35 \mathrm{~m}$ (height) is planned in the area. Figure 4 illustrates its sectional diagram.

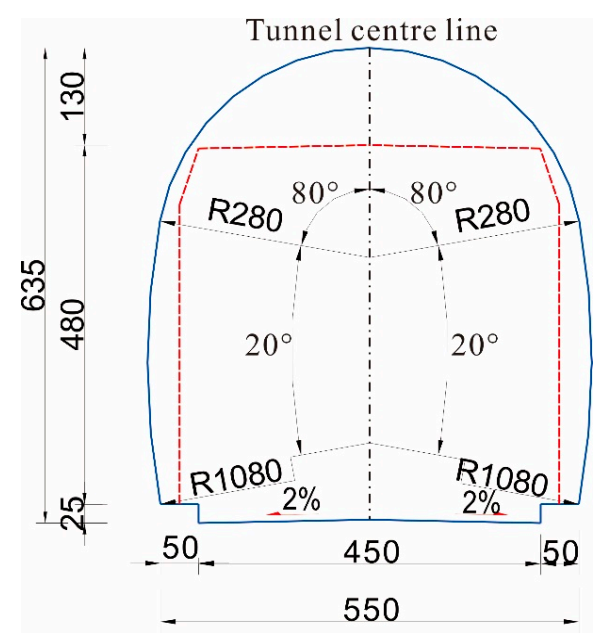

Figure 4. Sectional size drawing of the tunnel.

The exploration-results-based preliminary construction plan shows that the entrance location of the new tunnel will coincide with the existing tunnel location, and the axes of two will separate gradually. Moreover, the new tunnel section is adjacent to the slope and overlying road, so excavation expansion based on existing tunnels will certainly be detrimental to the slope and the road. These outcomes, combined with the results of the surrounding rock grade classification, clearly shows that the tunnel trunk section is distributed primarily with grade III rocks that have a rather high strength, quite intact rock masses, and are medium-thick layered with a good stability. Although the arch and side wall are fundamentally stable without support, excessive blasting vibration easily leads to collapse. To prevent the collapse of the existing tunnel caused by the blast working of new tunnel, backfilling of the existing tunnel is recommended prior to the excavation of the new tunnel. Meanwhile, smooth blasting and pre-split blasting technologies are adopted during the construction to achieve small-charge blasting with a vibration velocity not exceeding $1.5 \mathrm{~cm} / \mathrm{s}$ to minimize the disturbance to surrounding rocks and to ensure the safety and stability of the tunnel wall.

Since the new tunnel is close to the surfaces of the slope and ground, conducting a systematic study on the spatial positions of the new and existing tunnels is necessary on the premise of considering the in situ construction conditions comprehensively. In principle, the shallower the overburden of the new tunnel, the smaller its distance from the free face of the slope, and accordingly, the lower the construction cost. However, huge potential risks will be faced regarding engineering safety. Conversely, if the engineering safety is guaranteed, the construction cost will increase substantially. Furthermore, the surface load is also a crucial factor since the overlying road cannot be closed during construction. Meanwhile, whether concrete backfilling for the existing tunnel is implemented or not will also affect the displacement field distribution of the surrounding rocks after the tunnel excavation. Thus, whether backfilling of the existing tunnel is implemented is also included in the numerical study, and the backfill material is the same as the lining concrete material. Hence, this study needed to consider nine relative spatial positions of the new tunnel, three magnitudes of the surface load, and two backfilling conditions of the existing tunnel, which constitute a total of 54 models. Figure 5 illustrates the tunnel relationships under nine different spatial positions. 


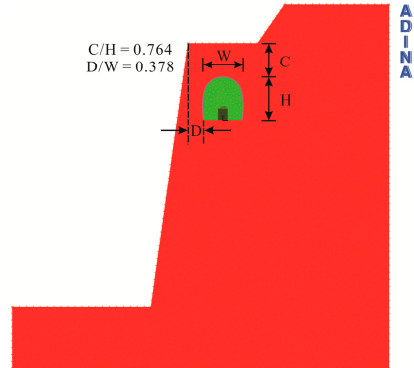

(a) A-A

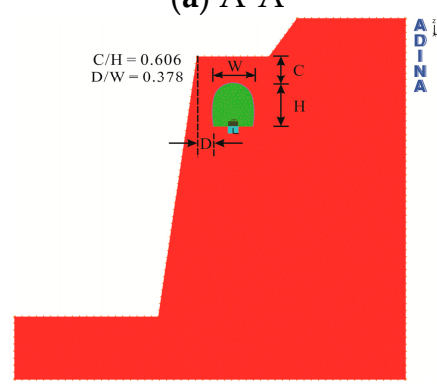

(d) D-D

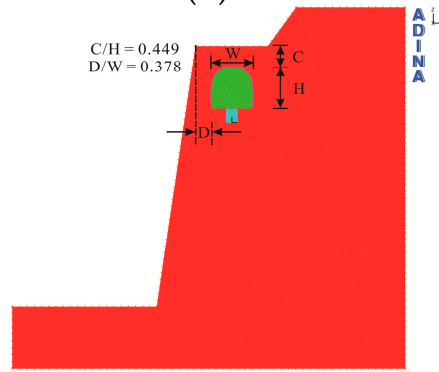

(g) G-G

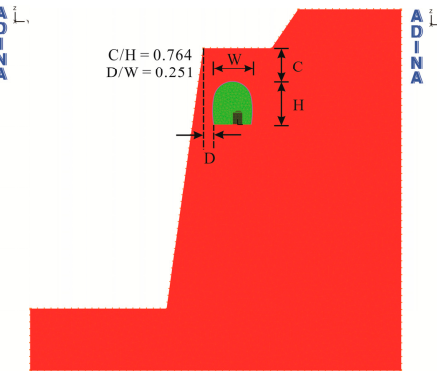

(b) B-B

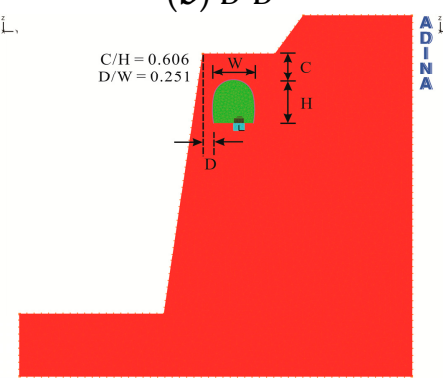

(e) E-E

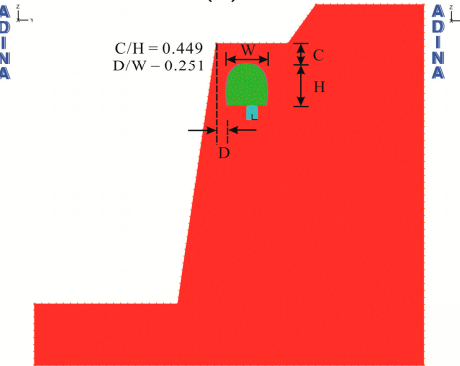

(h) $\mathrm{H}-\mathrm{H}$

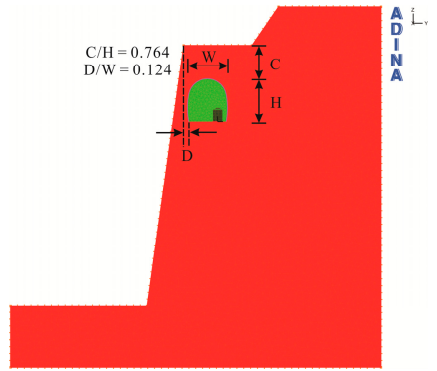

(c) C-C

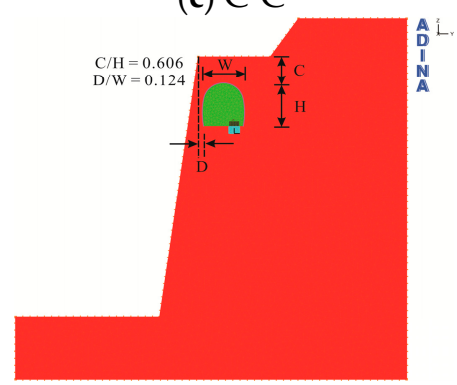

(f) F-F

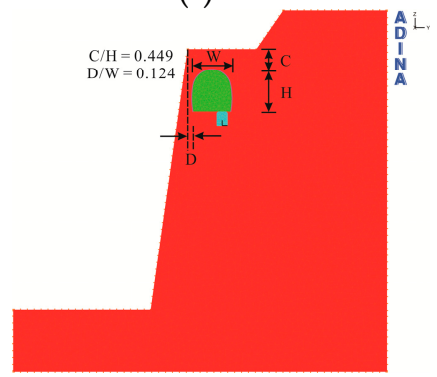

(i) I-I

Figure 5. Schematic of the nine spatial positions for the new tunnel.

As shown in Figure 5, the overburden, height, and width of the new tunnel was labeled C, H, and $\mathrm{W}$, respectively, while the distance from the tunnel to the vertical line of slope crest was labeled $\mathrm{D}$. Accordingly, this study considered a total of nine spatial position combinations when $\mathrm{C} / \mathrm{H}=0.764$, $\mathrm{C} / \mathrm{H}=0.606$, and $\mathrm{C} / \mathrm{H}=0.449$, as well as when $\mathrm{D} / \mathrm{W}=0.378, \mathrm{D} / \mathrm{W}=0.251$, and $\mathrm{D} / \mathrm{W}=0.124$. It is noteworthy that the overburden of the existing tunnel was $8.95 \mathrm{~m}$, and its distance from the adjacent slope was $4.23 \mathrm{~m}$.

The numerical model shown in Figure 6a had a 3D size of $100.0 \mathrm{~m} \times 54.2 \mathrm{~m} \times 52.7 \mathrm{~m}(\mathrm{~L} \times \mathrm{W} \times \mathrm{H})$, where the width of the road overlying the new tunnel was $10 \mathrm{~m}$, the vertical height of adjacent slope was $38.1 \mathrm{~m}$, and the slope angle was approximately $82^{\circ}$. An excavation simulation is performed on the new tunnel in the negative direction along the x-axis. The excavation method was full-face excavation, and the excavation cycle footage was $2.5 \mathrm{~m}$, and the model perspective is shown in Figure 6b. Both the tunnel and support were formed in one step. A composite lining of steel mesh and shotcrete was designed without considering the application of rebar, where the shotcrete had a strength grade of C25 and a spraying thickness of $100 \mathrm{~mm}$. The circumferential and longitudinal rebar meshes were spaced at $200 \mathrm{~mm}$, and the rebar diameter was $6.5 \mathrm{~mm}$. Additionally, according to the in situ investigation, a road closure measure could not be taken for the overlying road during the tunnel excavation; therefore, the surface surcharge in the model was simplified to a uniform load acting on the road surface, whose magnitude was considered to be $10 \mathrm{kPa}, 20 \mathrm{kPa}$, or $30 \mathrm{kPa}$ [10]. 


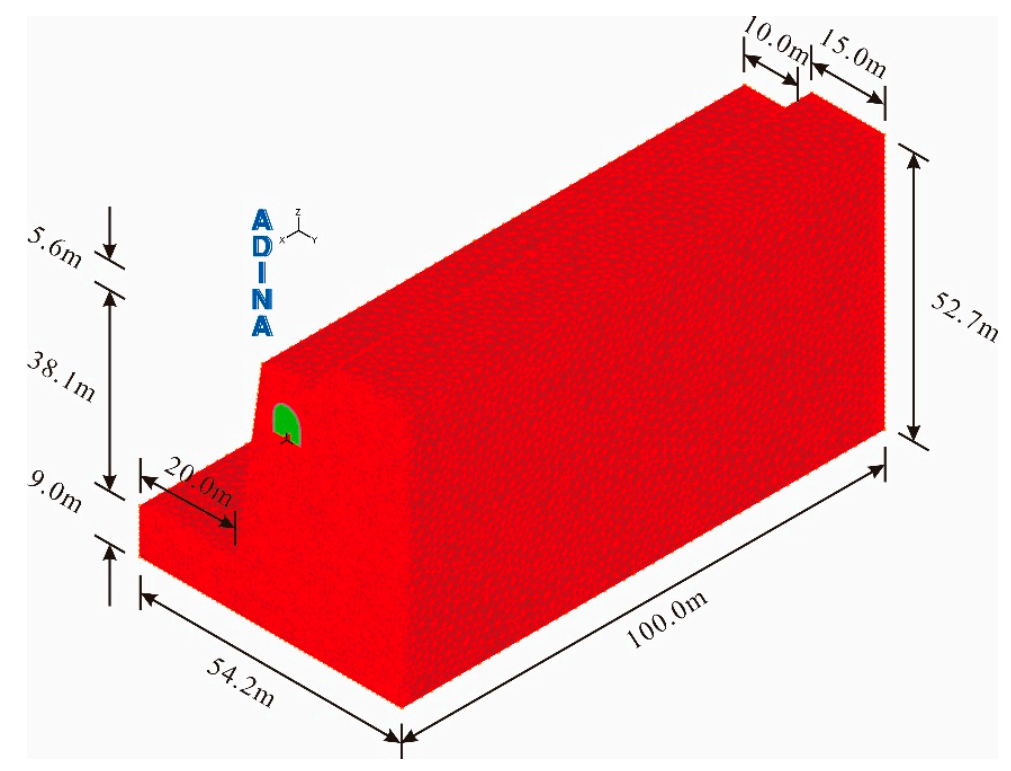

(a) Mesh plot

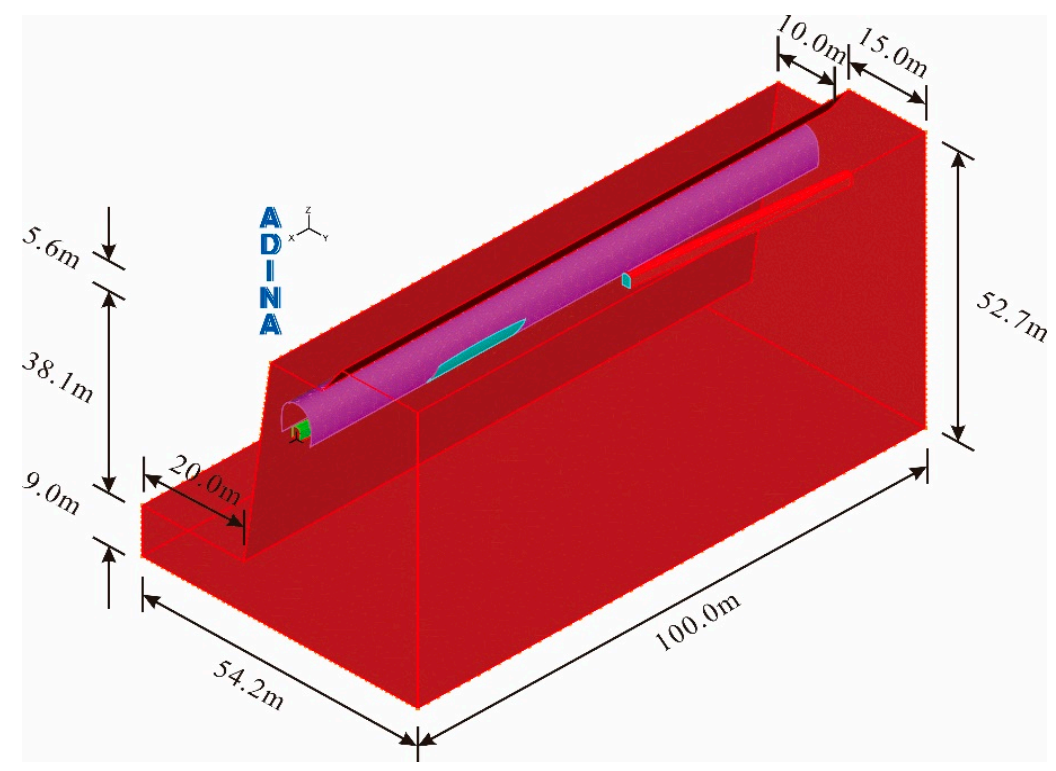

(b) Perspective plot

Figure 6. 3D size diagram of the numerical model.

The computational time was 80 steps for all numerical models, with a single step length of 1 . All odd-numbered computation steps simulated the rock mass excavation, while the even-numbered computation steps simulated the support structure generation. The rock masses (existing tunnel backfill concrete) were simulated with solid elements, whereas the lining structure was simulated with shell elements. A Mohr-Coulomb model was employed for the rock masses, while the elasticity constitutive model was used for the lining and backfill concrete. Tables 4 and 5 list the main computational parameters of the finite element models, where the rebar in Table 5 were used for locally reinforcing a small part of broken weathered rock at the tunnel portal section. The presence of these rebar was omitted in the numerical model, since the use of rebar was not considered in the design of the tunnel trunk supporting structure. Nevertheless, providing their mechanical parameters was still necessary. The permitted displacement boundary conditions were: no horizontal displacement down 
the all-vertical mesh boundaries, no vertical and horizontal displacement along the bottom boundary of the mesh, and freedom to displace along the top boundary. The total number of elements in each model was between 840,000 and 870,000 for all models. All the models were built by ADINA software (Version: 9.1.3, Chongqing University in Chongqing, China).

Table 4. Parameter selections of the rock mass in the finite element model.

\begin{tabular}{cccc}
\hline Stratum & Parameter & Range & Proposed Selection \\
\hline & $\mathrm{E}(\mathrm{GPa})$ & $1.1-2.6$ & 1.1 \\
$\mu$ & $0.30-0.33$ & 0.33 \\
Limestone & 2645 & 2645 \\
& $\rho\left(\mathrm{kg} \cdot \mathrm{m}^{-3}\right)$ & $30.2-33.5$ & 30.2 \\
& $\varphi\left(^{\circ}\right)$ & $0.45-0.55$ & 0.45 \\
$\mathrm{c}(\mathrm{MPa})$ & $1.35-1.82$ & 1.35 \\
\hline
\end{tabular}

E-elasticity modulus; $\mu$-Poisson ratio; $\rho$-density; $\varphi$-internal friction angle; $c$-cohesion; $\sigma_{\mathrm{t}}$-rock tensile strength.

Table 5. The medium parameters in the finite element physical and mechanical models.

\begin{tabular}{cccc}
\hline Medium & E (GPa) & $\left.\rho \mathbf{~} \mathbf{k g} \cdot \mathbf{m}^{-3}\right)$ & $\mu$ \\
\hline Rebar & 210 & 7800 & 0.30 \\
$\begin{array}{c}\text { C25 concrete for backfill } \\
\text { and lining }\end{array}$ & 28 & 2400 & 0.20 \\
\hline
\end{tabular}

\section{Analysis of the Numerical Results}

Considering that the tunnel excavation will lead to a redistribution of surrounding rock stress field, the displacement field of the surrounding rocks will also exhibit a corresponding distribution pattern with the adjustment of secondary stress [9]. In practical engineering, the variation course of the surrounding rock displacement field is generally studied more because the displacement of surrounding rocks is easier to measure than the stress state.

Direct quantitative evaluation of the feasibility, pros, and cons of the entire construction plan is possible via analyzing the effects of the tunnel excavation on the slope and road since the new tunnel is not only adjacent to the slope, but also buried shallowly under the road. As shown in Figure 7, the focus was on a comprehensive comparative analysis of the simulation results at five key locations: the road surface centerline (line A), the outer slope line of left tunnel sidewall center (line B), the separation boundary between existing tunnel and tunnel sidewall (line 1), the short-distance separation site between the existing tunnel and tunnel sidewall (line 2), and the long-distance separation site between the existing tunnel and tunnel sidewall (line 3).

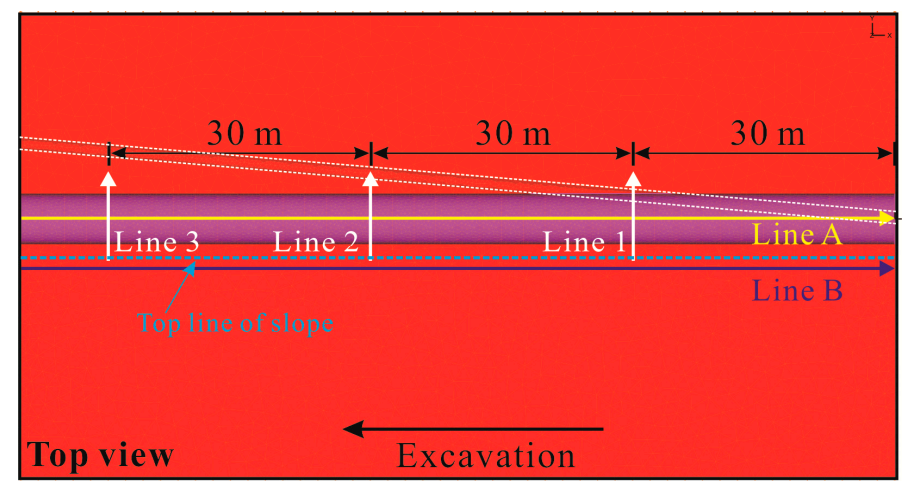

(a) $\mathrm{D} / \mathrm{W}=0.378$

Figure 7. Cont. 


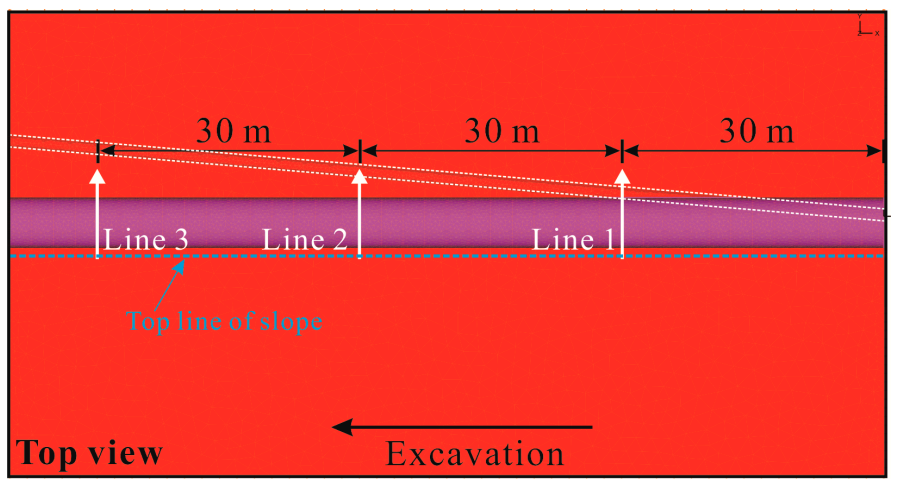

(b) $\mathrm{D} / \mathrm{W}=0.251$

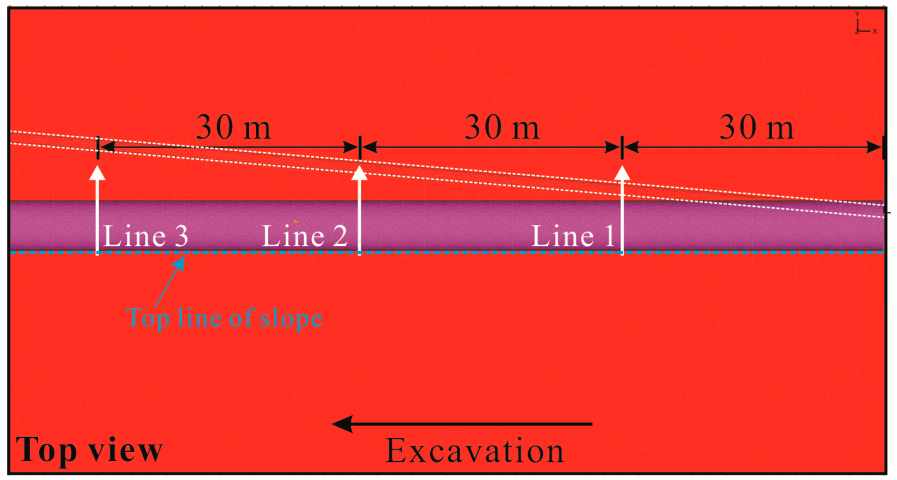

(c) $\mathrm{D} / \mathrm{W}=0.124$

Figure 7. Schematic of data extraction locations.

\subsection{Longitudinal Settlement of the Ground Surface}

\subsubsection{When $\mathrm{C} / \mathrm{H}=0.764$}

Figure 8 displays the final vertical settlement trends of the ground surface corresponding to different $\mathrm{D} / \mathrm{W}$ values at $\mathrm{C} / \mathrm{H}=0.764$. In the figure, the abscissa represents the construction distance and the ordinate represents the settlement value. Furthermore, A-A represents the model shown in Figure 5a, $10 \mathrm{kPa}$ represents the surface load magnitude, "htn" denotes that the existing tunnel was not backfilled, and "hty" denotes that the existing tunnel was backfilled. It is noteworthy that the model disallowed octahedral meshing due to the small angle skew of tunnel and the geometrical characteristics of the shallow burial and slope adjacency. Meanwhile, the change in the tunnel position will force a remeshing by the ADINA software since the model enabled the face-link forced-mesh continuity function. In other words, the mesh density was mandatorily and automatically adjusted by the software rather than being specified by manual code. It was thus normal for the simulation curves to have slight fluctuations.

As shown in Figure 8a, the surface settlement value at the boundary was rather large due to the boundary effect of the model, which can thus be ignored in the analysis. In the "htn" condition, the vertical settlement curves attributed to different surface loads were basically the same in shape. The settlement value increased with the increasing surface load, and the maximum settlements corresponding to $10 \mathrm{kPa}, 20 \mathrm{kPa}$, and $30 \mathrm{kPa}$ loads were $2.7 \mathrm{~mm}, 5.2 \mathrm{~mm}$, and $7.8 \mathrm{~mm}$, respectively. The settlement values in the "hty" conditions were very close to those in the "htn" condition, suggesting that the backfilling had a very limited effect on the surface settlement because the contour of the existing tunnel was included in the new tunnel at the initial excavation stage. When the existing tunnel began to intersect with the new tunnel, the backfilling of the existing tunnel directly affected the effective breadth of the tunnel, which thereby affected the adjustment of the secondary stress and displacement fields of the surrounding rocks. Therefore, this area was defined as the sensitive zone. 
The maximum settlement difference caused by the tunnel being backfilled was located at $65 \mathrm{~m}$ (at a tunnel excavation length of $35 \mathrm{~m}$ ), where the existing tunnel was just separated from the new tunnel, as shown in Figure 7a. For the three surface loads of $10 \mathrm{kN} / \mathrm{m}^{2}, 20 \mathrm{k} \mathrm{N} / \mathrm{m}^{2}$, and $30 \mathrm{k} \mathrm{N} / \mathrm{m}^{2}$, the settlements following backfilling of the existing tunnel decreased by $63.2 \%$, $48.5 \%$, and $41.5 \%$, respectively, as compared to the non-backfilling condition. This fully proved that the existing tunnel backfilling was effective in controlling the surface settlement. After a further increase in the distance between the existing and new tunnels, the existing tunnel no longer produced a significant effect on the surface settlement; therefore, this area was defined as the unaffected zone. The ground settlement law shown in Figure 8b was basically consistent with Figure 8a. However, since the tunnel began to shift toward the slope direction, the location with a maximum difference in the influence of existing tunnel backfill on surface settlement was precisely the site at which the existing tunnel just separated itself from the new tunnel. At this point, the tunnel excavation distance was approximately $26 \mathrm{~m}$, as shown in Figure $7 \mathrm{~b}$. Additionally, the difference in surface settlement caused by the existing tunnel being backfilled for tunnel excavation was more pronounced than that in Figure 8a within an excavation range of 90-100 $\mathrm{m}$ due to the slight reduction in the length of the existing tunnel that was included in the excavation face.

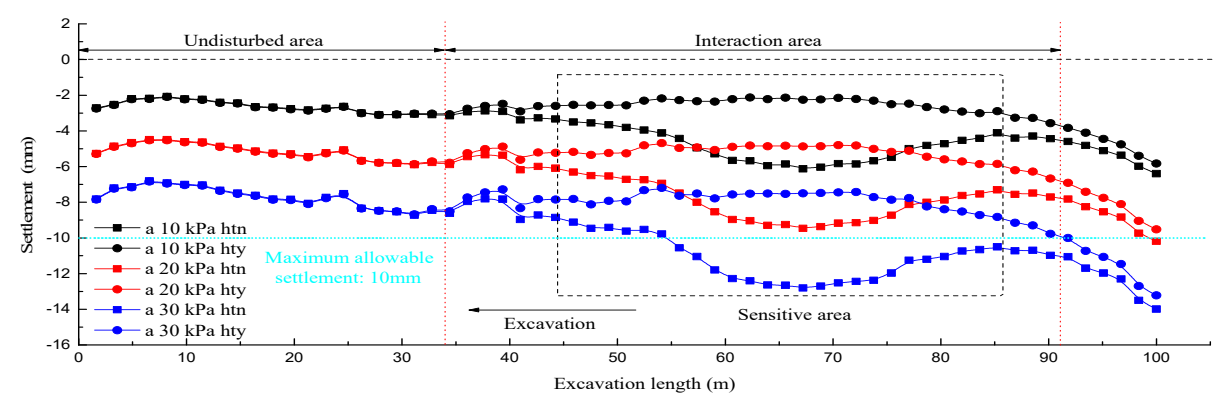

(a) $\mathrm{D} / \mathrm{W}=0.378$

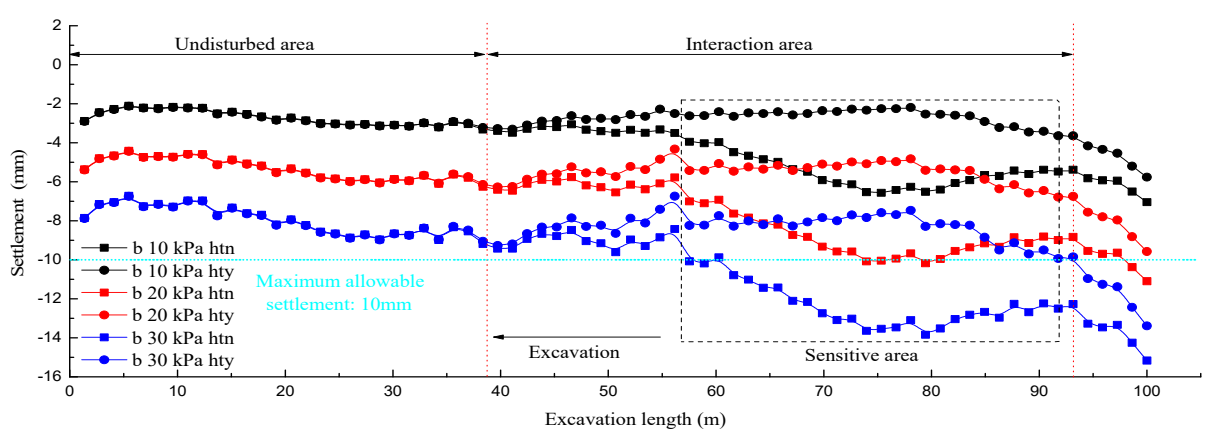

(b) $\mathrm{D} / \mathrm{W}=0.251$

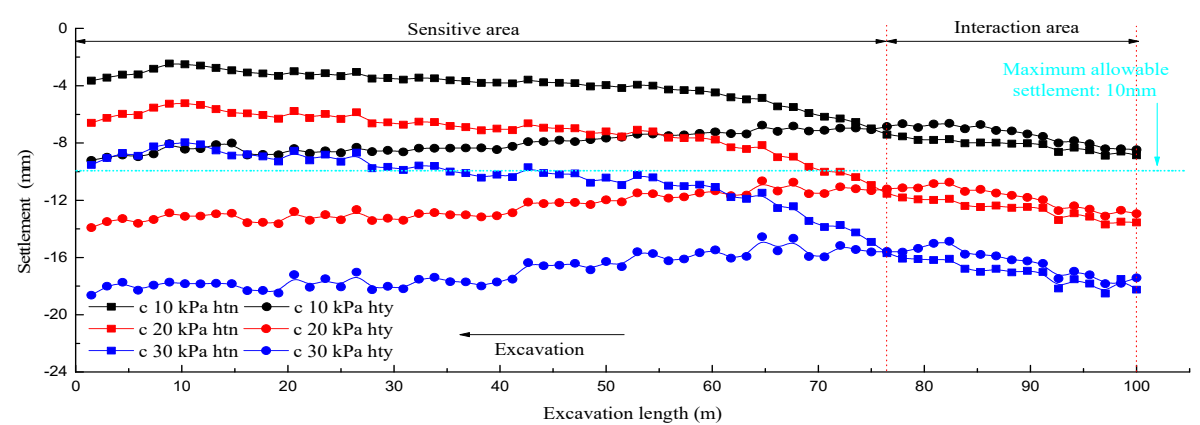

(c) $\mathrm{D} / \mathrm{W}=0.124$

Figure 8. Longitudinal surface settlement of models A-A to C-C. 
Finally, a comparison with Figure $8 \mathrm{c}$ shows the emergence of a new law regarding the settlement trends. That is, the difference in surface settlement was small at the overlapping zone of the existing and new tunnels, which increased significantly after the new tunnel was separated from the existing tunnel. Meanwhile, backfilling of the existing tunnel aggravated the ground surface deformation. The main reason was found to be the excessively small $\mathrm{D} / \mathrm{W}$ ratio of the new tunnel, at which point the thickness of slope rock pillar became the primary controlling factor of tunnel stability. After the tunnel excavation, the slope rock pillars were displaced toward the tunnel interior, while the lateral deformation of the surrounding rocks was coordinated and restricted by the settlement deformation of rocks in the tunnel upper part. Hence, when the existing tunnel was backfilled, the horizontal span of the new tunnel was reduced. At this time, a considerably higher $\mathrm{C} / \mathrm{H}$ ratio than the $\mathrm{D} / \mathrm{W}$ ratio made the surface settlement more severely affected by the lateral deformation such that the settlement became larger as well. On the contrary, when the existing tunnel was not backfilled, the span of the new tunnel could be considered to increase such that the enlarged $\mathrm{C} / \mathrm{H}$ ratio also caused an enhanced ability to suppress the lateral deformation. Therefore, the settlement value decreased instead at this time. After repeated trial computations, $\mathrm{D} / \mathrm{W}=0.16$ was determined as the critical position where the surface settlement exhibited the opposite law at $\mathrm{C} / \mathrm{H}=0.764$.

\subsubsection{When $\mathrm{C} / \mathrm{H}=0.606$ and $\mathrm{C} / \mathrm{H}=0.449$}

The surface settlement laws reflected in Figure 9 a,b were basically consistent with Figure $8 a, b$. The only difference lay in the increased surface settlement after the $\mathrm{C} / \mathrm{H}$ reduction, with an average increase of approximately $4.3-7.6 \%$. Meanwhile, the settlement law resumption in Figure $8 \mathrm{c}$ was consistent with the laws in Figure 8a,b. The sensitive zone for the influence of the existing tunnel backfilling on settlement was also located at the junction of tunnels. As can be seen from Figure 7c, a tunnel excavation distance of about $15 \mathrm{~m}$ remained the most sensitive area. Furthermore, the settlement law in Figure 10 was also consistent with Figure 9. A comparison revealed that the increase in displacement at the sensitive zone was also more significant than that at the non-disturbed zone.

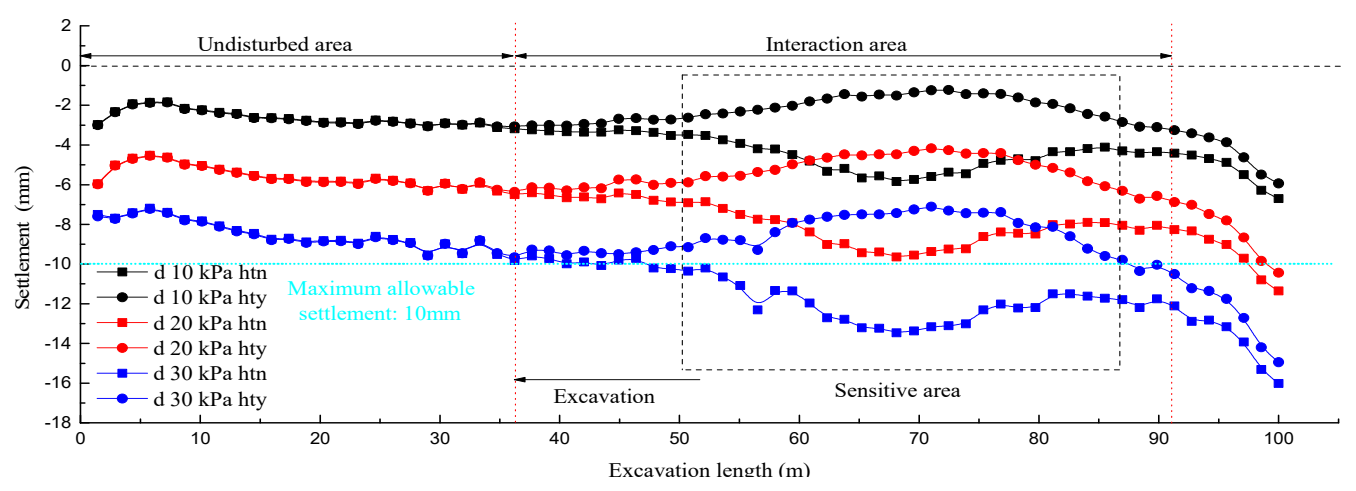

(a) $\mathrm{D} / \mathrm{W}=0.378$

Figure 9. Cont. 


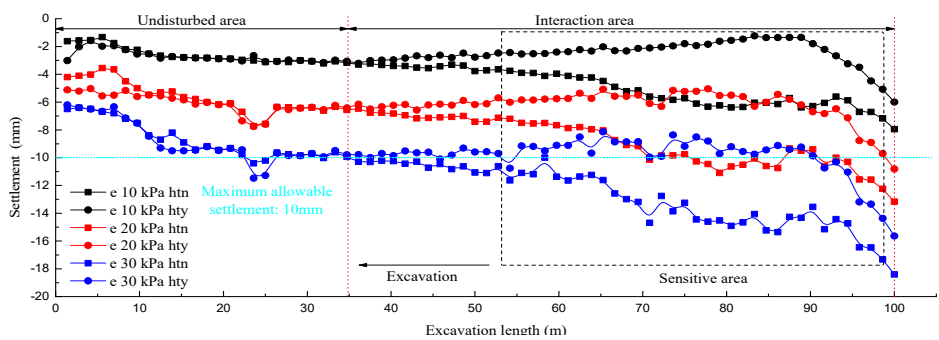

(b) $\mathrm{D} / \mathrm{W}=0.251$

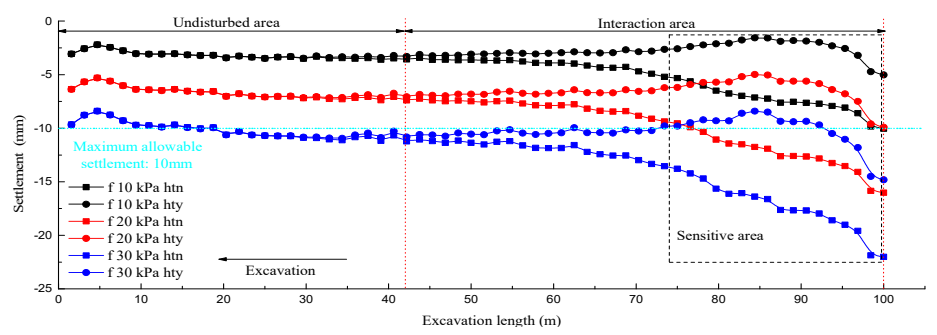

(c) $\mathrm{D} / \mathrm{W}=0.124$

Figure 9. Longitudinal surface settlement of models D-D to F-F with $\mathrm{C} / \mathrm{H}=0.606$.

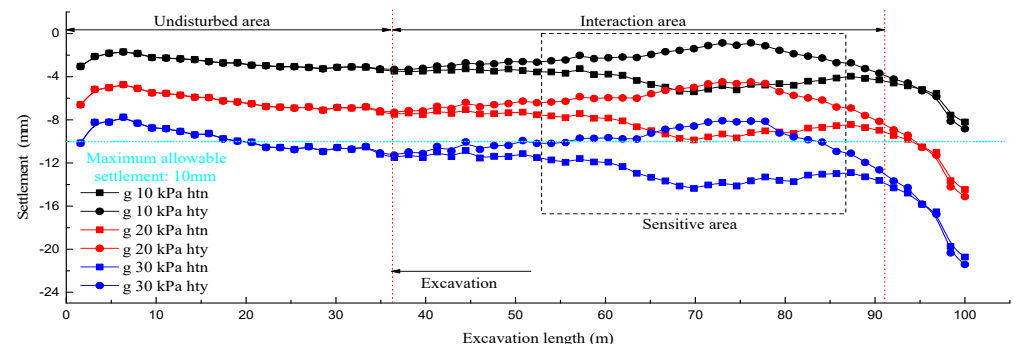

(a) $\mathrm{D} / \mathrm{W}=0.378$

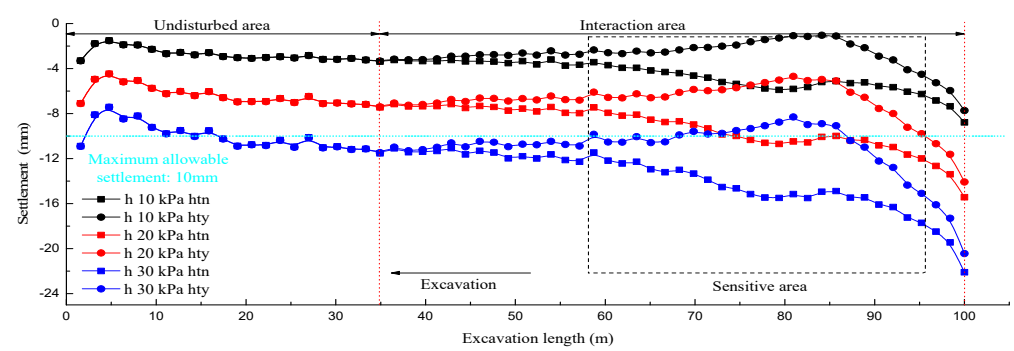

(b) $\mathrm{D} / \mathrm{W}=0.251$

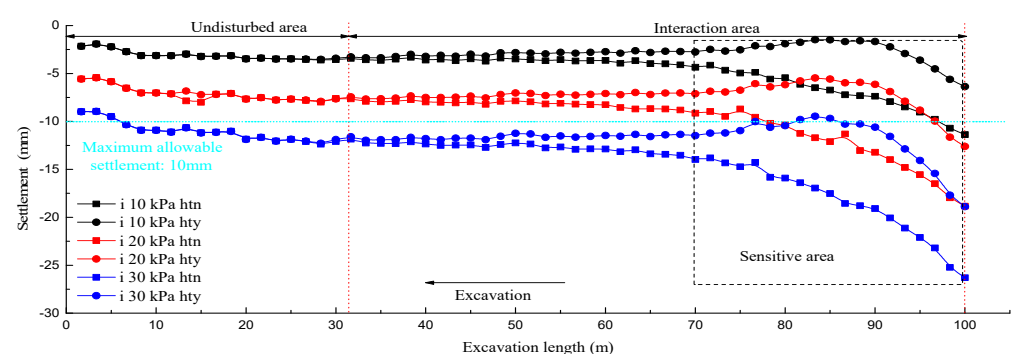

(c) $\mathrm{D} / \mathrm{W}=0.124$

Figure 10. Longitudinal surface settlement of models $\mathrm{G}-\mathrm{G}$ to $\mathrm{I}-\mathrm{I}$ with $\mathrm{C} / \mathrm{H}=0.449$. 


\subsection{Transverse Settlement of the Ground Surface}

\subsubsection{When $\mathrm{C} / \mathrm{H}=0.764$}

According to the findings of similar surface settlement studies, the maximum settlements resulting from a single-cavern excavation are almost all located at the tunnel axis position. Thus, to better reflect the relevant influence characteristics of intersecting tunnels on the surface deformation, this section continued to analyze the lateral settlement law of the ground surface. As shown in Figure 7, a settlement research line was arranged at $30 \mathrm{~m}$ intervals from the excavation direction. The three lines separately corresponded to three special spatial locations: the sites of critical separation, and the short-distance and long-distance separations of the new tunnel from the existing tunnel.

First, it is clear from Figure 11 that the increase in the surface load also caused greater settlement, and that the settlement trough shapes of the curves are distinct. According to Figure 11a, the backfilling of the existing tunnel was markedly influential on the surface settlement at this time. The maximum settlement was about $11.6 \mathrm{~mm}$ in the absence of backfilling, while it was only $8.3 \mathrm{~mm}$ in the presence of backfilling, showing a decrease of approximately $28.4 \%$. At line 2, the difference in settlement attributed to the existing tunnel backfilling was reduced to about $20 \%$, while at line 3 , such a difference was already inconspicuous. This fully explained why the distance from the existing tunnel to the new tunnel was also a sensitive factor affecting the surface settlement. Additionally, as the centerline of new tunnel coincided with the centerline of the overlying road at $\mathrm{D} / \mathrm{W}=0.378$, the symmetry axis of the settlement trough curve coincided with the tunnel and road centerlines in the "hty" condition. Furthermore, in the "htn" condition, the symmetry axis of the settlement trough curve shifted toward the existing tunnel direction. This kind of phenomena has also been studied by many scholars. With the continuous separation of the new tunnel from the existing tunnel, the corresponding surface settlement continued to decrease as well. Eventually, the maximum settlement at line 3 was approximately 7.6 $\mathrm{mm}$, and the symmetry axes of all settlement curves coincided.

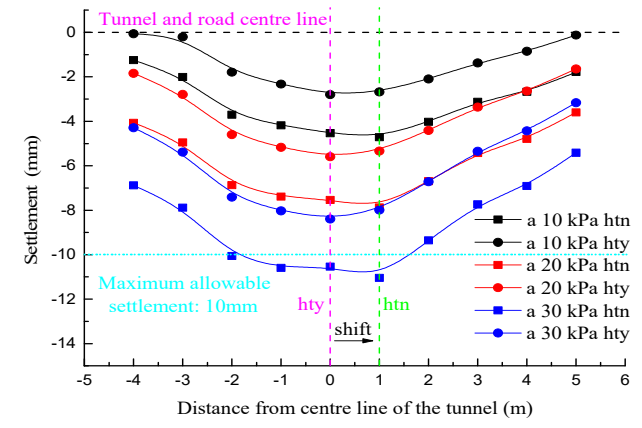

(a) Line 1

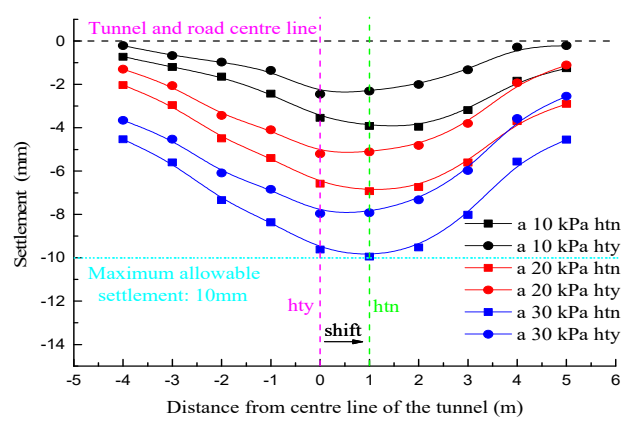

(b) Line 2

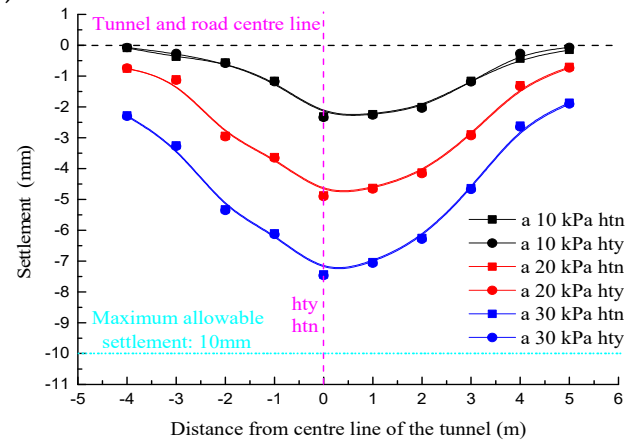

(c) Line 3

Figure 11. Longitudinal surface settlement of model A-A with $\mathrm{D} / \mathrm{W}=0.378$. 
Figure 12 also reflects a relevant law. The maximum settlements at lines 2 and 3 changed insignificantly compared to Figure 13, although the maximum settlement corresponding to the "htn" condition shown in Figure 14a was close to $14 \mathrm{~mm}$. This again explained why the intersection (line 1) between the new and existing tunnels was a sensitive zone that affected the change of the surface settlement at a constant $\mathrm{C} / \mathrm{H}$ ratio of 0.764 . Furthermore, a comparison of Figures 11a and 12a shows that the D/W reduction affected the settlement in the "htn" condition only. The root cause was an inconsistency of the effective tunnel span at line 1 in the "htn" condition. Thus, "htn" was a sensitive factor influencing settlement at this time.

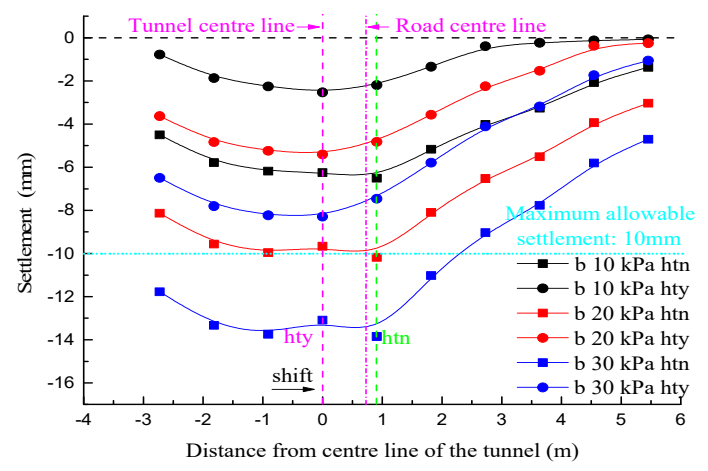

(a) Line 1

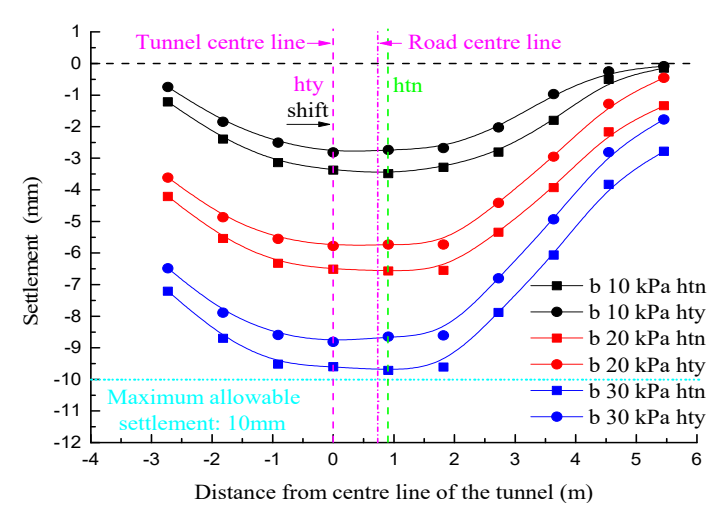

(b) Line 2

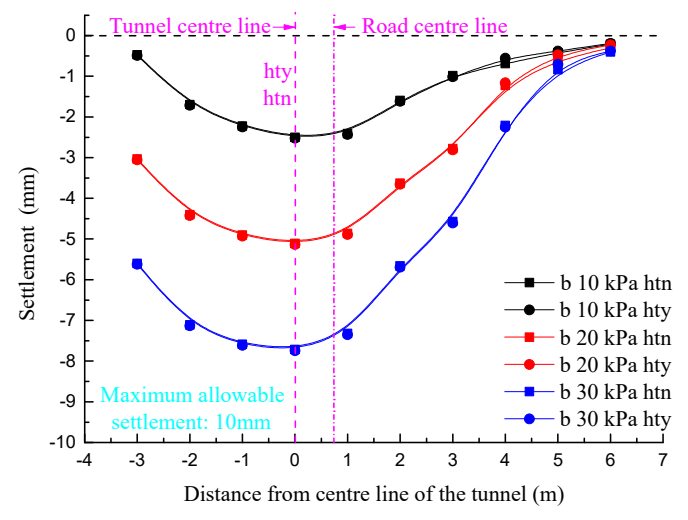

(c) Line 3

Figure 12. Longitudinal surface settlement of model B-B with $\mathrm{D} / \mathrm{W}=0.251$.

When $\mathrm{D} / \mathrm{W}=0.251$, lines 1 and 2 were deviated from the tunnel axis such that the symmetry axis of the settlement curve was biased to the left of the road centerline in the "hty" condition. In contrast, in the "htn" condition, the symmetry axis of the settlement curve was biased to the right of the road centerline. Moreover, in view of the far smaller sectional size of the existing tunnel than the new tunnel, the eccentricity of the settlement curve symmetry axis in the "htn" condition was significantly lower than that in the "hty" condition. On the other hand, the symmetry axes of all the settlement curves for line 3 shown in Figure 12c coincided with the tunnel center, which were still located on the left side of road centerline as well. The settlement value was affected only by the surface load magnitude.

The settlement law presented in Figure 13 differs from that in Figures 11 and 12, and the cause of such a difference has been explained earlier. From Figure 13, it can be seen that with the further decrease of $\mathrm{D} / \mathrm{W}=0.124$, the deviation of the settlement curve symmetry axis from the road centerline was aggravated further in the "hty" condition. At this point, the symmetry axis position of the settlement trough curve in the "htn" condition lay between the two instead. Meanwhile, the abrupt changes in the settlement value and trend suggested that there must be a critical $\mathrm{D} / \mathrm{W}$ value at $\mathrm{C} / \mathrm{H}=0.764$ that 
led the settlement law to change abruptly. After repeated trial computations, the critical D/W ratio was determined to be approximately 0.16 . This implied that the maximum surface settlement was not merely controlled by $\mathrm{C} / \mathrm{H}$, but was also affected by $\mathrm{D} / \mathrm{W}$. The two parameters together determined the magnitude of the settlement. Therefore, we could directly decide according to the settlement magnitude that the model C-C should not be included in the consideration of a feasible construction plan.

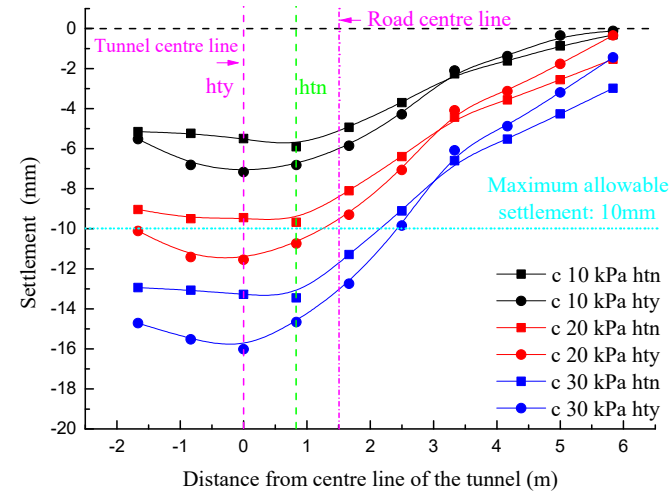

(a) Line 1

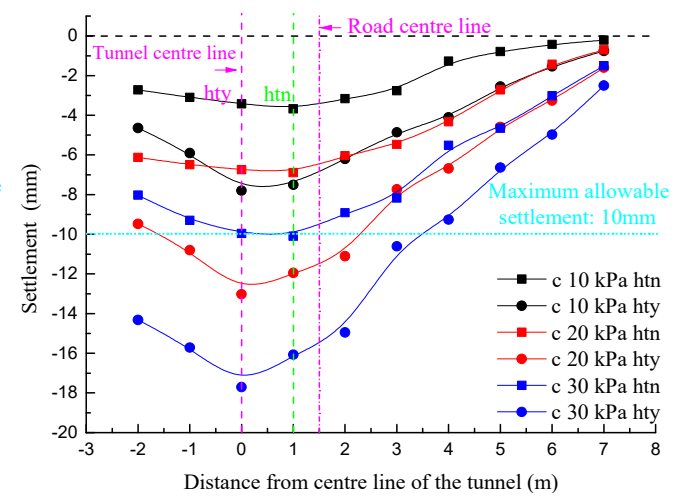

(b) Line 2

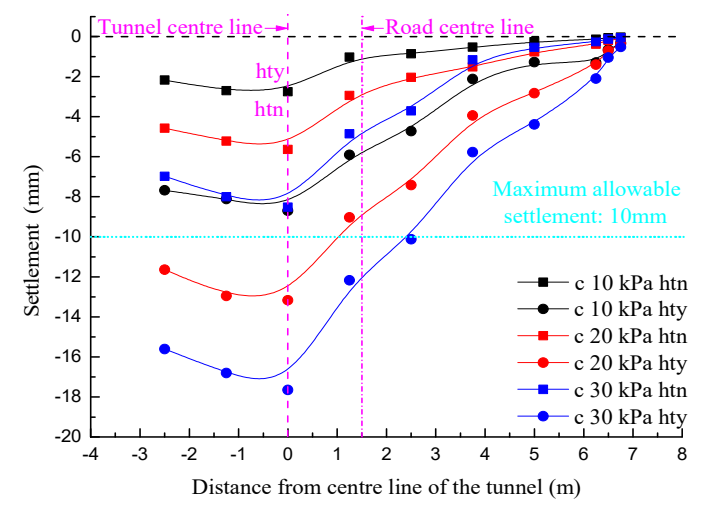

(c) Line 3

Figure 13. Longitudinal surface settlement of model C-C with $D / W=0.124$.

\subsubsection{When $\mathrm{C} / \mathrm{H}=0.606$}

With the decline of the $\mathrm{C} / \mathrm{H}$ ratio to 0.606 , the difference in the settlement caused by the "hty" and "htn" conditions was also widened, and the maximum surface deformation at line 1 could be up to 13.4 $\mathrm{mm}$, as shown in Figure 14a. However, under a fixed C/H ratio, the maximum settlements at lines 1-3 decreased sequentially with the increasing spacing between the tunnels. As the overburden of the new tunnel became shallower, the intersection area between the existing and new tunnels shrunk. Thus, the difference in settlement resulting from the existing tunnel being backfilled for line 2 was weakened compared to Figure 11b. Moreover, as shown in Figures 14b, 15b and 16b, the symmetry axes of the settlement curves were no longer obviously affected by the existing tunnel. The settlement differences in Figures 14c, 15c and 16c were even less apparent due to the tunnel spacing. Figure 15 shows a similar law to Figure 14, despite the symmetry axes of all settlement curves coinciding with the tunnel centerline, and their deviation distance from the overlying road center was $0.75 \mathrm{~m}$. In Figure 16, such a deviation increased to $1.5 \mathrm{~m}$. 


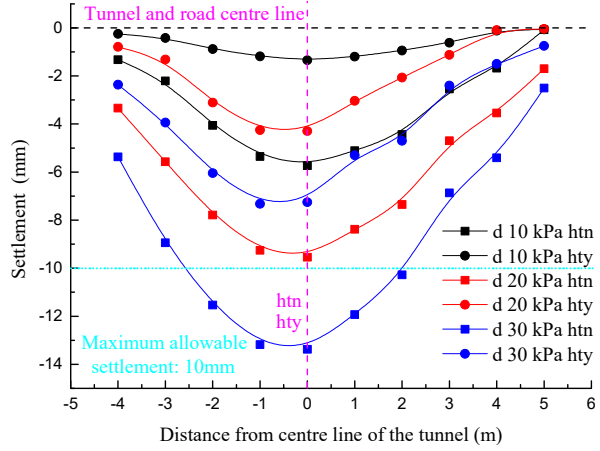

(a) Line 1

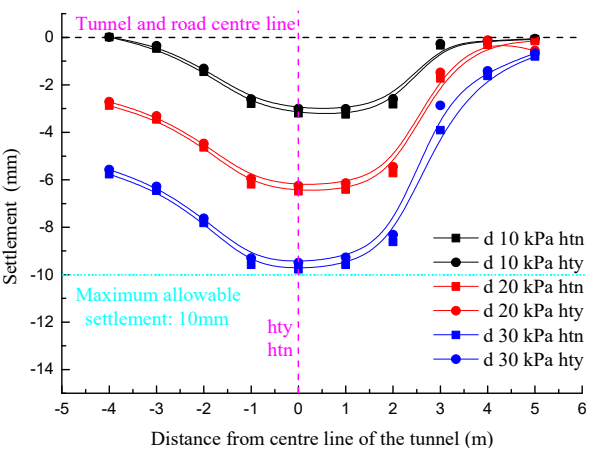

(b) Line 2

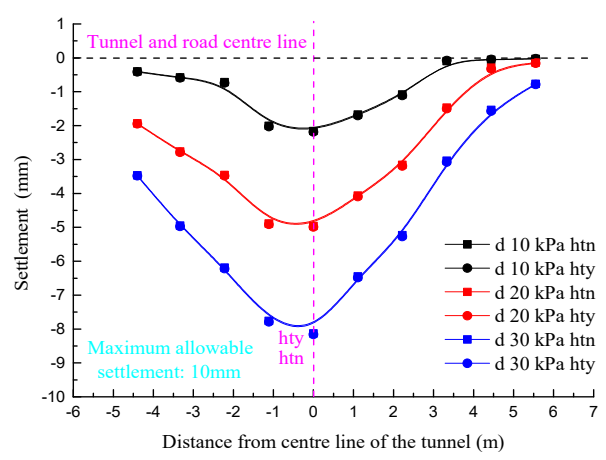

(c) Line 3

Figure 14. Longitudinal surface settlement of model D-D with $\mathrm{D} / \mathrm{W}=0.378$.

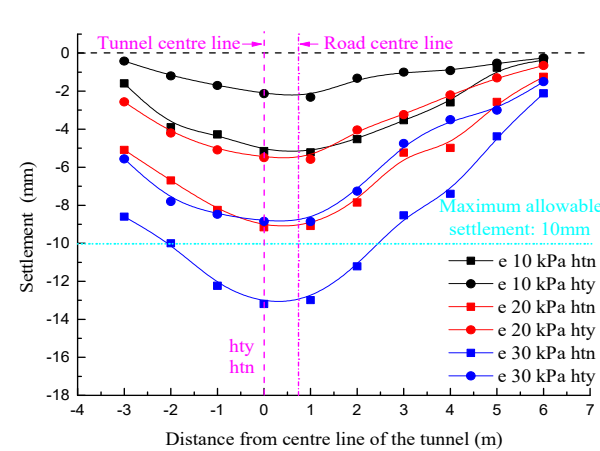

(a) Line 1

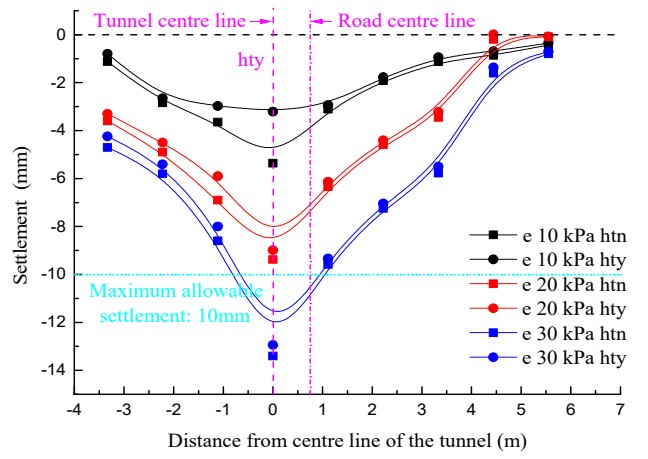

(b) Line 2

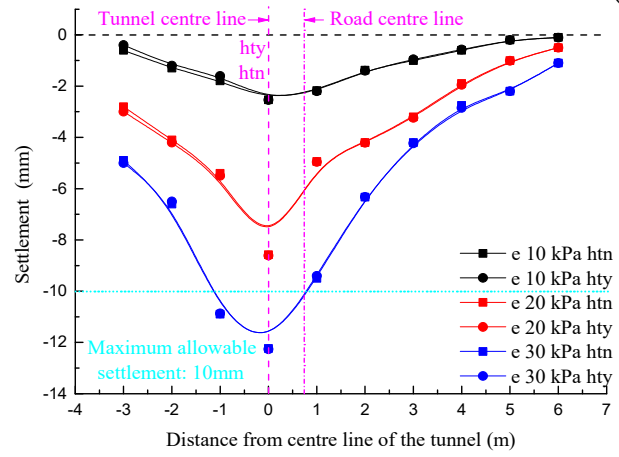

(c) Line 3

Figure 15. Longitudinal surface settlement of model E-E with $\mathrm{D} / \mathrm{W}=0.251$. 


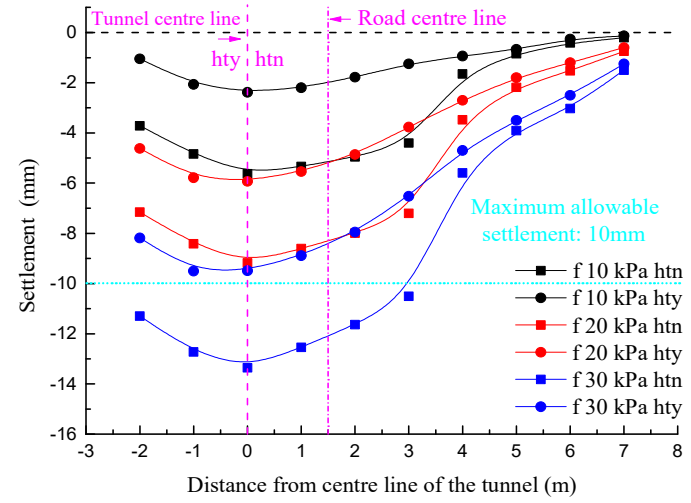

(a) Line 1

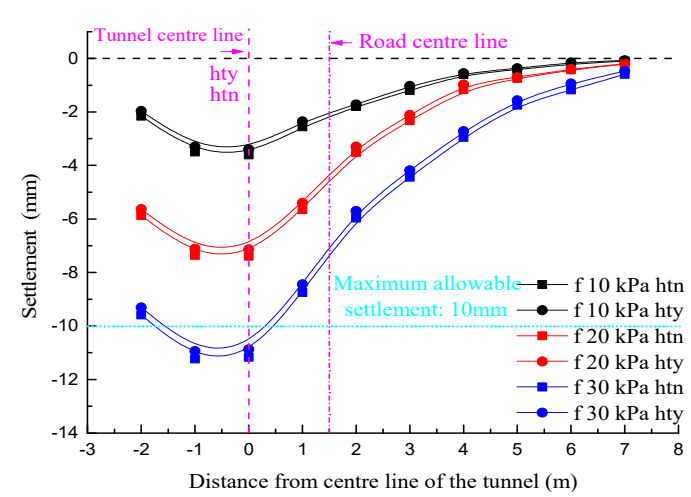

(b) Line 2

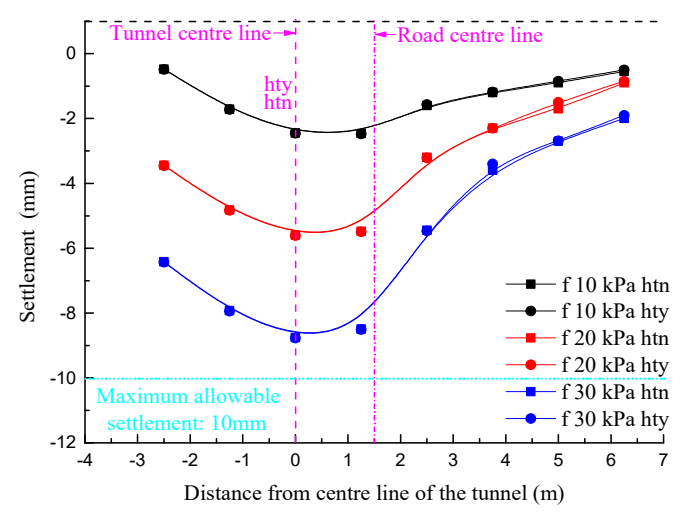

(c) Line 3

Figure 16. Longitudinal surface settlement of model F-F with $\mathrm{D} / \mathrm{W}=0.124$.

According to the above research results, the line 1 region was a sensitive zone affecting the surface settlement. Thus, a comparison of Figures 14a, 15a and 16a revealed that the settlement changed indistinctly with various surface loads in the "htn" condition of $\mathrm{C} / \mathrm{H}=0.606$, showing a trend opposite to that at $\mathrm{C} / \mathrm{H}=0.764$. This was because the backfilling of the existing tunnel only affected the span of new tunnel when $\mathrm{C} / \mathrm{H}=0.764$. In contrast, when $\mathrm{C} / \mathrm{H}=0.606$, the spatial effect of the existing tunnel backfilling on the new tunnel changed from the mere effect on the span to the joint effect on the height and span. The effective height of the new tunnel could be considered invariant when the existing tunnel was not backfilled such that the change in settlement was indistinct. In the "hty" condition, however, the height turned into a sensitive influential factor on the line 1 region. Further comparison of Figure 14b,c, Figure 15b,c and Figure 16b,c found the largest settlement with model E-E under the same conditions. Thus, it could be inferred that the surface settlement was controlled jointly by the $\mathrm{C} / \mathrm{H}$ and $\mathrm{D} / \mathrm{W}$ ratios, and the difference in the control weight between the two meant that the settlement results presented different laws. Therefore, the correctness of the settlement law described in this section needs further verification by integrating the simulation results into the $\mathrm{C} / \mathrm{H}=0.449$ condition.

\subsubsection{When $\mathrm{C} / \mathrm{H}=0.449$}

As the comparison of Figures 17a, 18a and 19a reveals, the settlements at the sensitive zone line 1 also changed indistinctly in the "htn" condition, but more significantly than those in Figures 14a, 15a and 16a in the "hty" condition. The reason was that the backfilling of existing tunnels was directly and completely influential to the height of new tunnel after the excavation. Furthermore, a comparison of Figure 17b,c, Figure 18b,c and Figure 19b,c reveals the largest settlement with model I-I under the same conditions. 


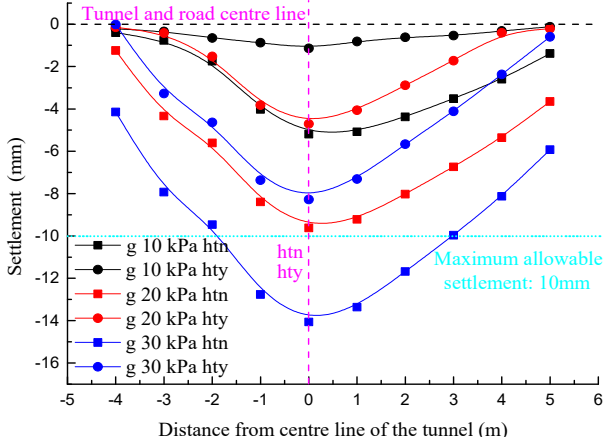

(a) Line 1

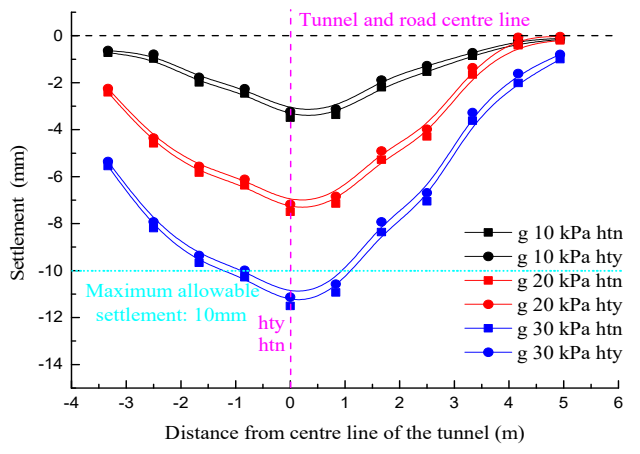

(b) Line 2

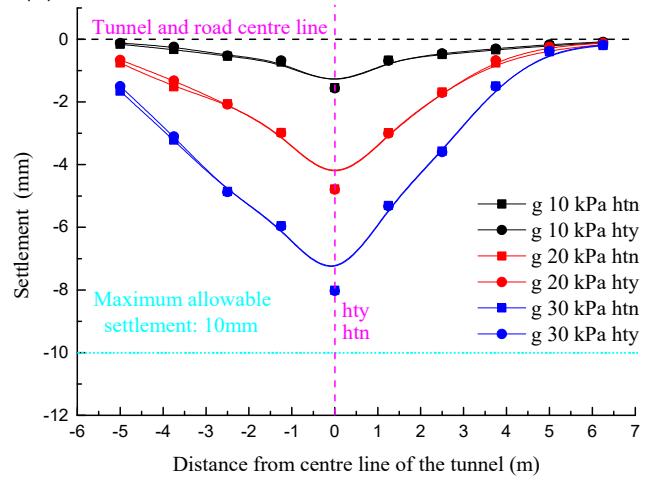

(c) Line 3

Figure 17. Longitudinal surface settlement of model G-G with $\mathrm{D} / \mathrm{W}=0.378$.

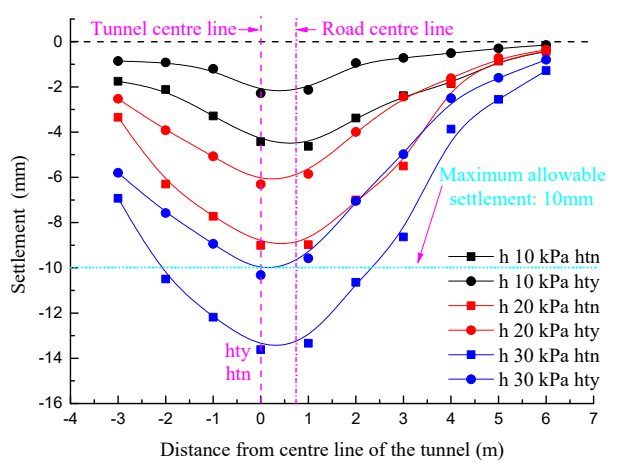

(a) Line 1

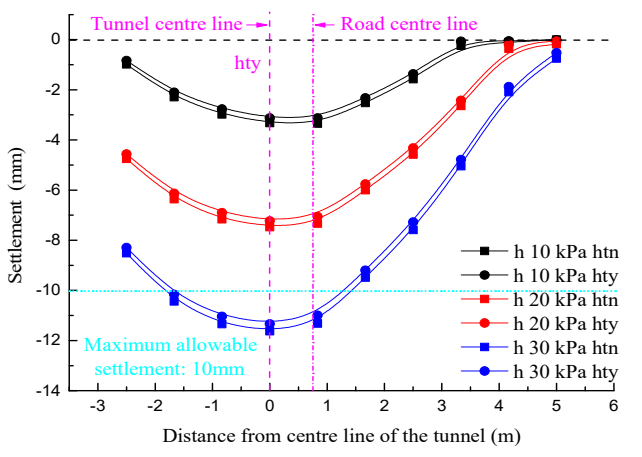

(b) Line 2

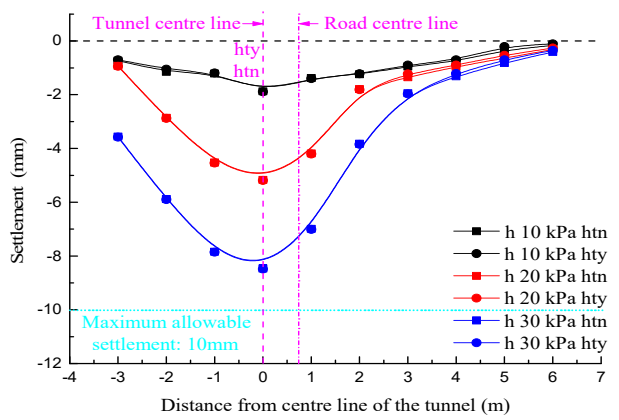

(c) Line 3

Figure 18. Longitudinal surface settlement of model $\mathrm{H}-\mathrm{H}$ with $\mathrm{D} / \mathrm{W}=0.251$. 


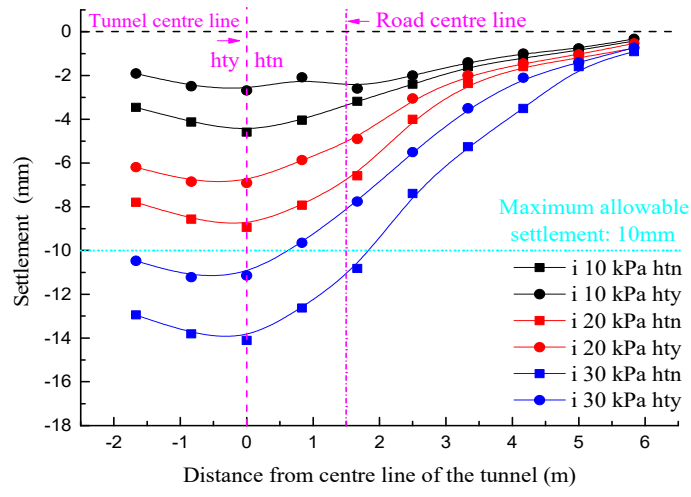

(a) Line 1

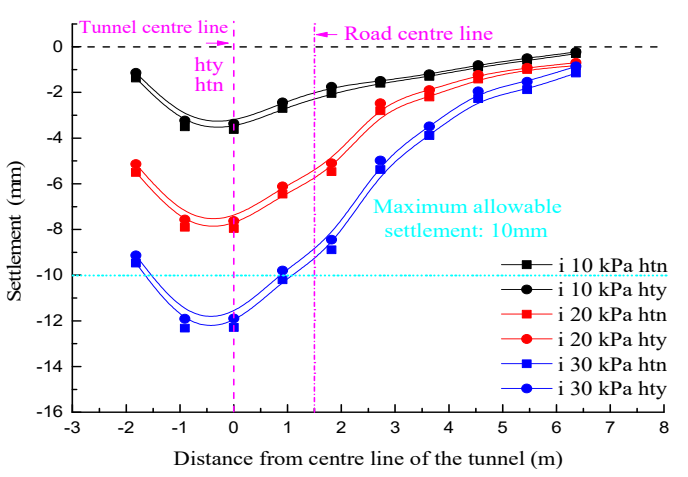

(b) Line 2

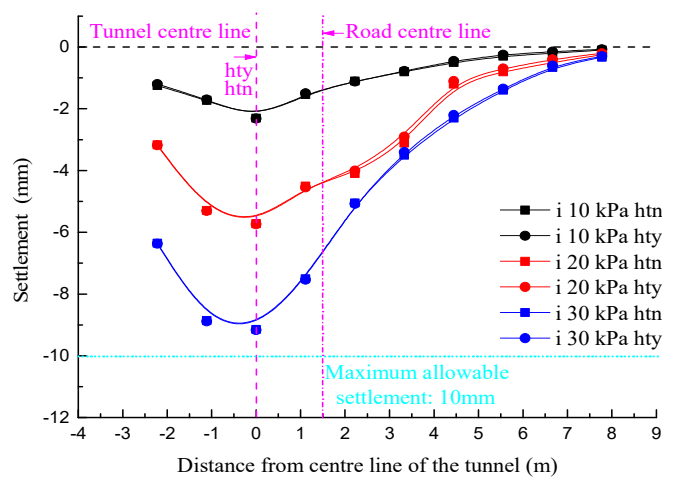

(c) Line 3

Figure 19. Longitudinal surface settlement of model I-I with $\mathrm{D} / \mathrm{W}=0.124$.

\subsection{Lateral Deformation of the Slope}

The slope deformation trends reflected in Figures 20-22 are fundamentally analogous to the vertical settlement laws of the ground surface, which was attributed to the continuous coordinated deformation of the surrounding rocks. The trends of the slope deformation again explained why the intersection between the two tunnels was the sensitive zone affecting the surface settlement and slope deformation. As shown in Figure 21a-c, with the decrease in the D/W ratio, the boundary between the non-disturbed and interaction zones also increased slightly in the opposite direction of the excavation. Hence, further screening of a feasible construction plan is needed based on the slope deformation values in different conditions.

\subsection{Comparison of Construction Plans}

To ensure the engineering safety, the upper limit of the surface settlement was set to $10 \mathrm{~mm}$, while the maximum lateral deformation of slope should not exceed $5.5 \mathrm{~mm}$. The computational results of the 54 models are summarized in Table 6 for screening. As is clear, the models represented by blue fonts can all preliminarily satisfy the construction requirements according to the upper limit requirements of the surface settlement and slope deformation. However, three magnitudes of surface load were taken into account in the models, of which a $10 \mathrm{kPa}$ load corresponded to a relatively low late-night traffic load; $20 \mathrm{kPa}$ corresponded to a daily traffic load; and $30 \mathrm{kPa}$ corresponded to a heavy traffic load (mainly the load of heavy-duty, full-load trucks, including the transportation of building materials and waste soil in this project). It can thus be seen from Table 6 that all models except for model A-A met the safety requirements at a $10 \mathrm{kPa}$ load, while at a $20 \mathrm{kPa}$ load, the safety requirements could only be satisfied by backfilling the existing tunnels. No model met the safety requirements at a $30 \mathrm{kPa} l o a d$. Traffic control can hardly be implemented during construction due to the large traffic volume in the 
project site. From the engineering safety perspective, the maximum surface load should be considered, so model A-A ("hty" condition) is the only feasible model among all models. Accordingly, the in situ construction of a new tunnel must be carried out in strict accordance with model A-A while making adequate monitoring efforts.

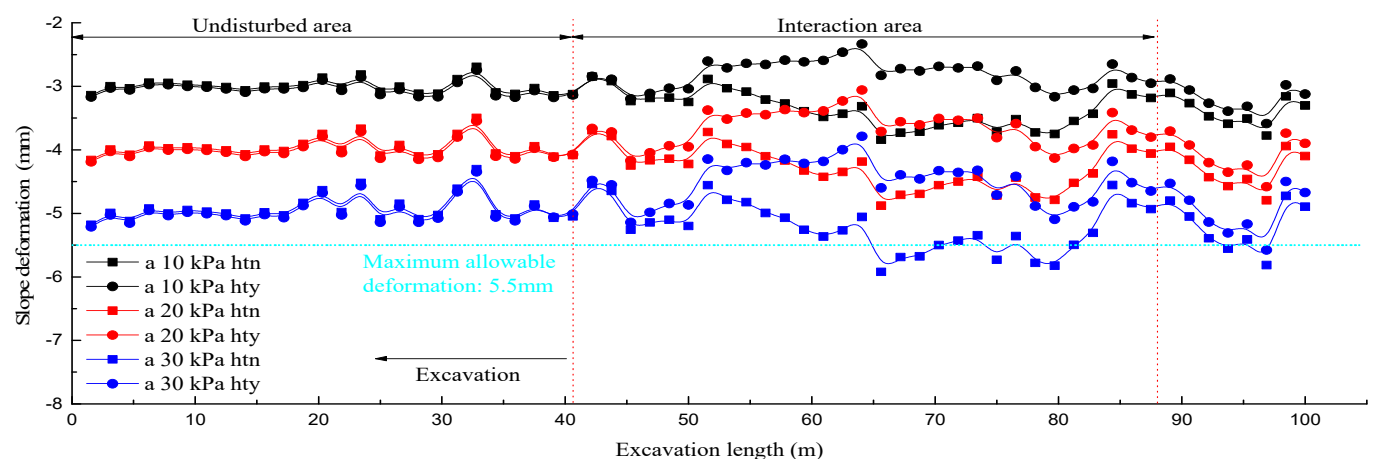

(a) $\mathrm{D} / \mathrm{W}=0.378$

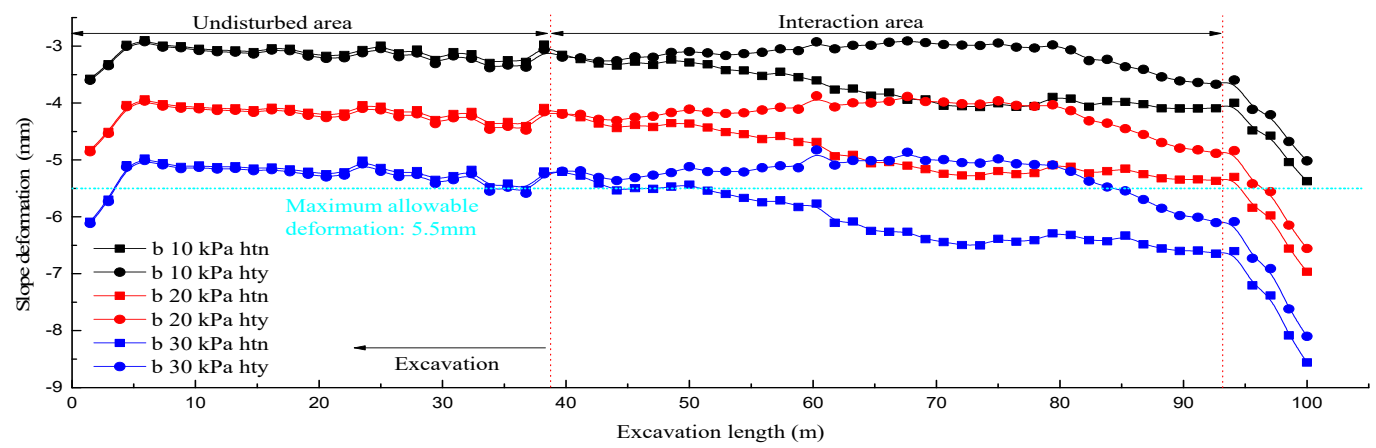

(b) $\mathrm{D} / \mathrm{W}=0.251$

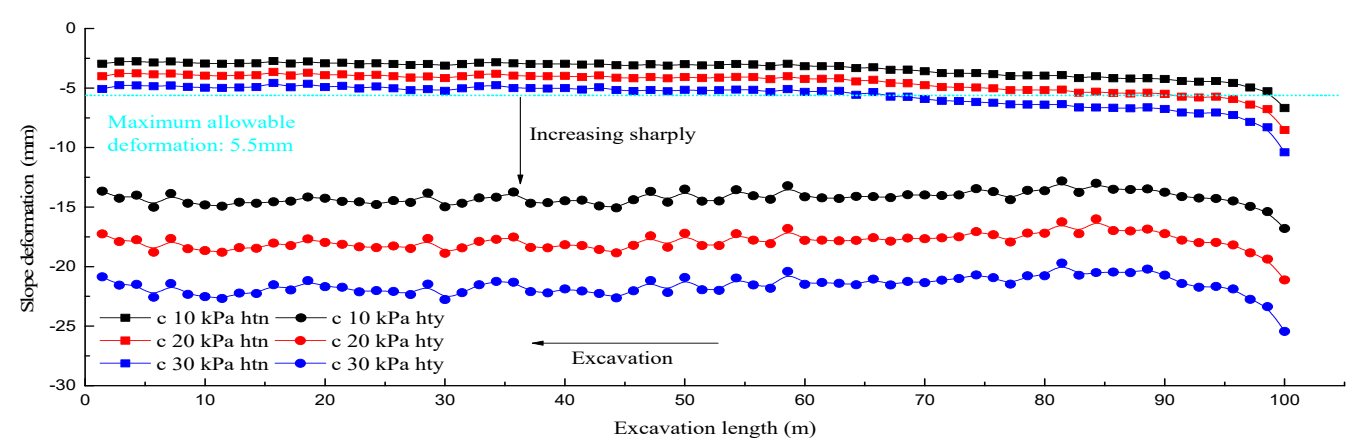

(c) $\mathrm{D} / \mathrm{W}=0.124$

Figure 20. Longitudinal surface settlement of models A-A to $\mathrm{C}-\mathrm{C}$ with $\mathrm{C} / \mathrm{H}=0.764$. 


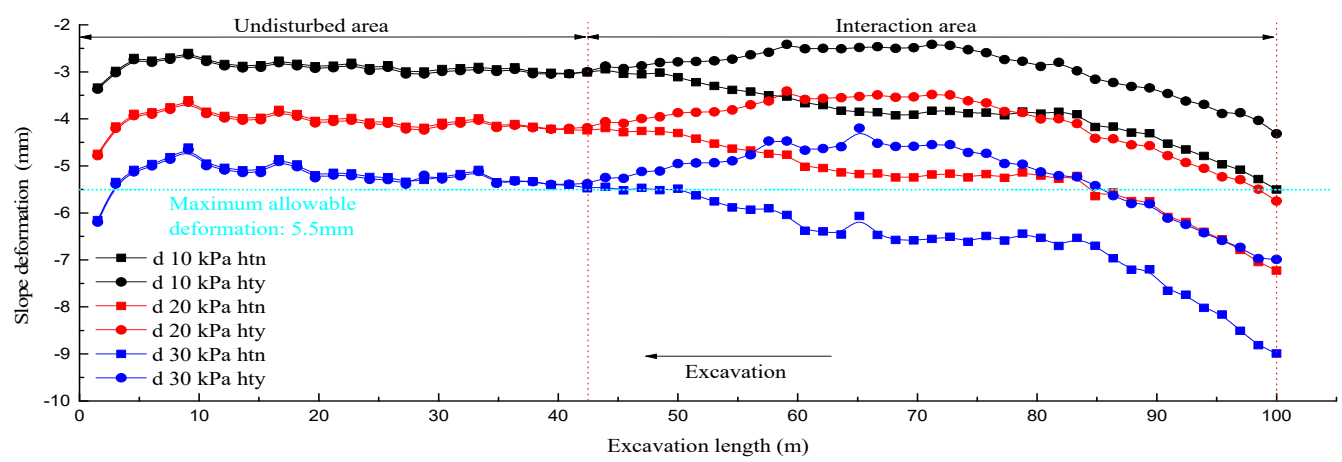

(a) $\mathrm{D} / \mathrm{W}=0.378$

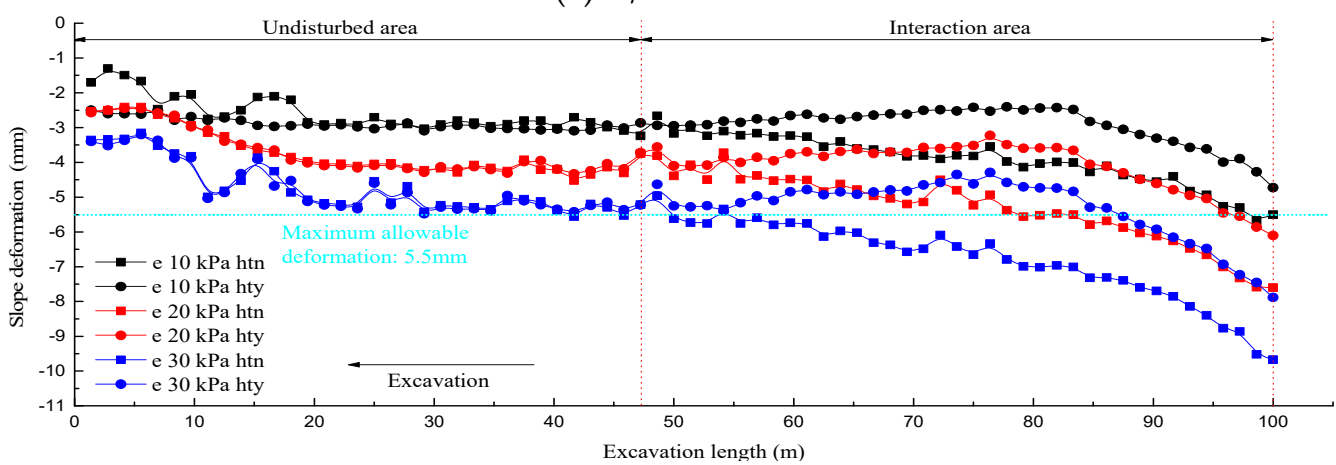

(b) $\mathrm{D} / \mathrm{W}=0.251$

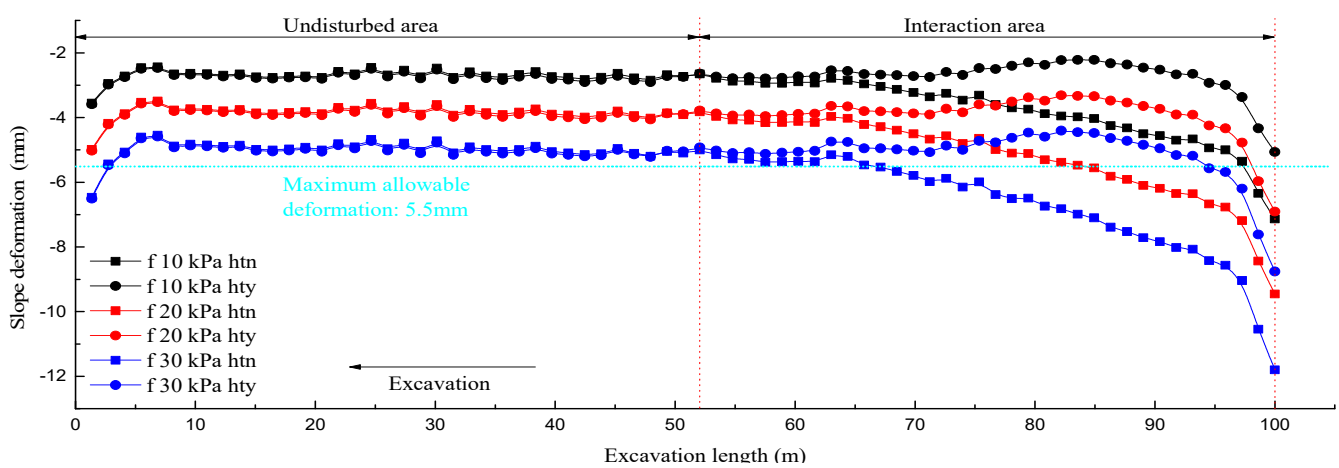

(c) $\mathrm{D} / \mathrm{W}=0.124$

Figure 21. Longitudinal surface settlement of models D-D to F-F with $\mathrm{C} / \mathrm{H}=0.606$. 


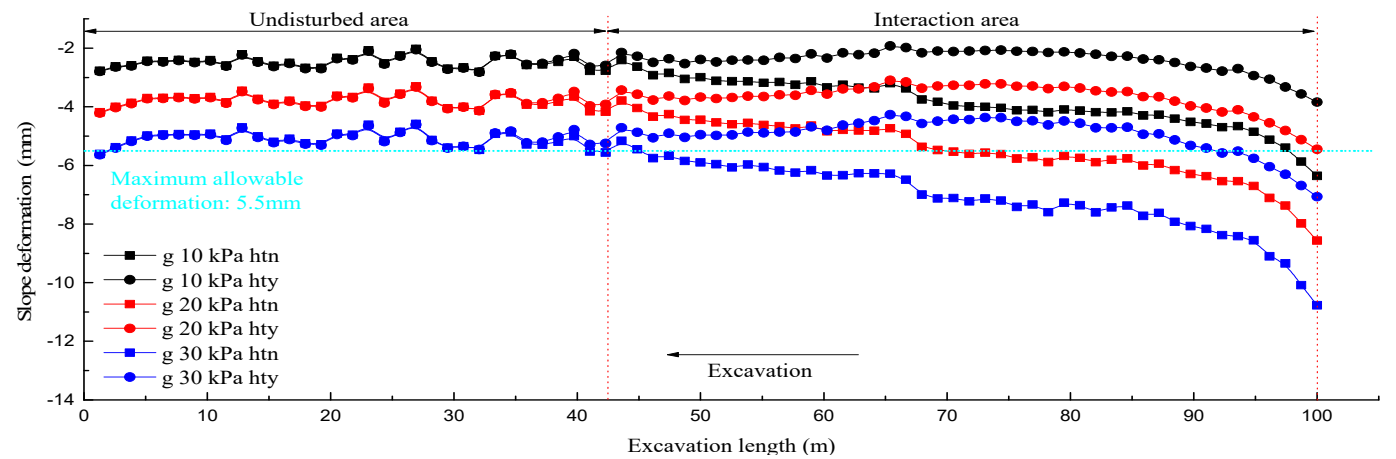

(a) $\mathrm{D} / \mathrm{W}=0.378$

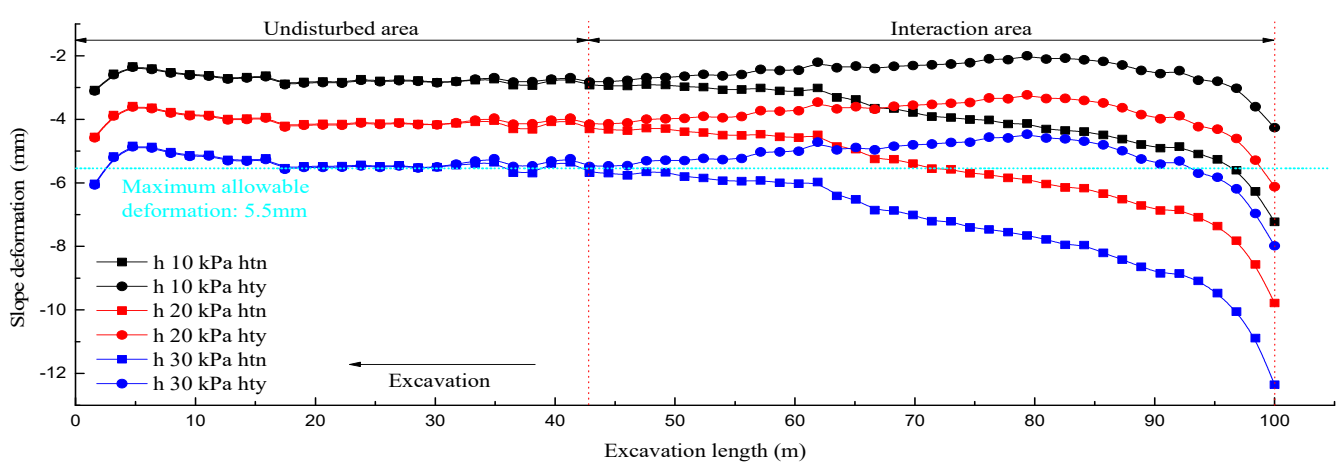

(b) $\mathrm{D} / \mathrm{W}=0.251$

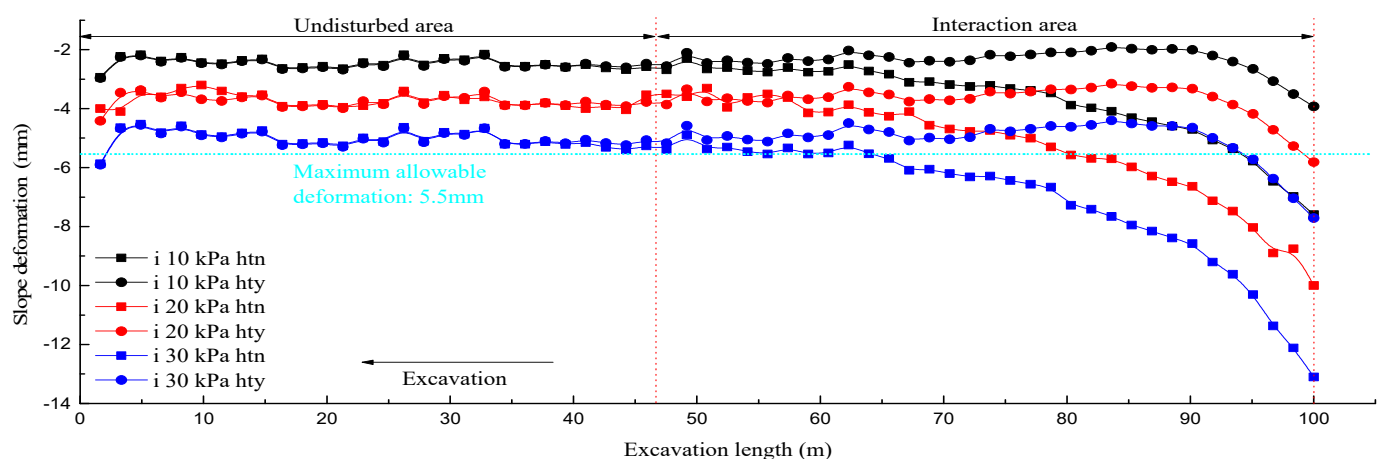

(c) $\mathrm{D} / \mathrm{W}=0.124$

Figure 22. Longitudinal surface settlement of models G-G to I-I with $\mathrm{C} / \mathrm{H}=0.449$. 
Table 6. Summary of the displacement calculations for all models.

\begin{tabular}{|c|c|c|c|c|c|c|c|c|}
\hline Model & $\mathrm{C} / \mathrm{H}$ & $\mathrm{D} / \mathrm{W}$ & $\begin{array}{l}\text { Surcharge } \\
(\mathbf{k P a})\end{array}$ & $\begin{array}{l}\text { Existing } \\
\text { Tunnel } \\
\text { Condition }\end{array}$ & $\begin{array}{c}\text { Surface } \\
\text { Settlement } \\
\text { Upper Limit } \\
\text { (mm) }\end{array}$ & $\begin{array}{l}\text { Maximum } \\
\text { Computed } \\
\text { Settlement } \\
\quad(\mathrm{mm})\end{array}$ & $\begin{array}{c}\text { Slope } \\
\text { Deformation } \\
\text { Upper Limit } \\
(\mathrm{mm})\end{array}$ & $\begin{array}{c}\text { Maximum } \\
\text { Computed } \\
\text { Settlement } \\
(\mathrm{mm})\end{array}$ \\
\hline \multirow{6}{*}{ A-A } & \multirow{18}{*}{0.764} & \multirow{6}{*}{0.378} & \multirow[b]{2}{*}{10} & htn & & 6.1 & & 3.2 \\
\hline & & & & hty & & 3.5 & & 3.0 \\
\hline & & & \multirow{2}{*}{20} & htn & & 9.4 & & 4.1 \\
\hline & & & & hty & & 6.6 & & 3.9 \\
\hline & & & \multirow{2}{*}{$\underline{30}$} & htn & & 12.8 & & 5.3 \\
\hline & & & & hty & & 9.5 & & $\underline{4.7}$ \\
\hline \multirow{6}{*}{ B-B } & & & \multirow{2}{*}{10} & htn & & 6.5 & & 4.0 \\
\hline & & & & hty & & 3.6 & & 3.6 \\
\hline & & & \multirow[b]{2}{*}{20} & htn & & 10.0 & & 5.3 \\
\hline & & 0.251 & & hty & & 6.8 & & 4.9 \\
\hline & & & \multirow[b]{2}{*}{30} & htn & & 13.5 & & 6.6 \\
\hline & & & & hty & & 9.9 & & 6.1 \\
\hline \multirow{6}{*}{ C-C } & & \multirow{6}{*}{0.124} & \multirow{2}{*}{10} & htn & & 8.0 & & 4.4 \\
\hline & & & & hty & & 8.9 & & 14.1 \\
\hline & & & \multirow[b]{2}{*}{20} & htn & & 12.5 & & 5.7 \\
\hline & & & & hty & & 13.6 & & 17.8 \\
\hline & & & \multirow[b]{2}{*}{30} & htn & & 17.0 & & 7.1 \\
\hline & & & & hty & & 18.3 & & 21.4 \\
\hline \multirow{6}{*}{ D-D } & & & \multirow{2}{*}{10} & htn & & 5.8 & & 4.6 \\
\hline & & & & hty & & 3.2 & & 3.7 \\
\hline & & & & htn & & 9.6 & & 6.2 \\
\hline & & 0.378 & 20 & hty & & 6.9 & & 4.9 \\
\hline & & & & htn & & 13.4 & & 7.7 \\
\hline & & & 30 & hty & & 10.5 & & 6.2 \\
\hline & & & & htn & 10 & 6.4 & 5.5 & 4.8 \\
\hline & & & 10 & hty & & 2.7 & & 3.6 \\
\hline & 0.606 & & & htn & & 10 & & 6.5 \\
\hline E-E & & 0.251 & 20 & hty & & 6.8 & & 5.0 \\
\hline & & & & htn & & 14.4 & & 8.1 \\
\hline & & & 30 & hty & & 10.7 & & 6.3 \\
\hline & & & & htn & & 7.9 & & 4.7 \\
\hline & & & 10 & hty & & 3.9 & & 2.6 \\
\hline & & & & htn & & 13.2 & & 6.4 \\
\hline F-F & & 0.124 & 20 & hty & & 7.1 & & 3.9 \\
\hline & & & & htn & & 18.6 & & 8.1 \\
\hline & & & 30 & hty & & 10.8 & & 5.2 \\
\hline & & & & htn & & 4.6 & & 4.7 \\
\hline & & & 10 & hty & & 4.2 & & 2.8 \\
\hline & & & & htn & & 9.4 & & 6.5 \\
\hline G-G & & 0.378 & 20 & hty & & 8.9 & & 4.2 \\
\hline & & & & htn & & 14.3 & & 8.4 \\
\hline & & & 30 & hty & & 13.6 & & 5.6 \\
\hline & & & & htn & & 5.7 & & 4.9 \\
\hline & & & 10 & hty & & 3.2 & & 2.8 \\
\hline & 0.449 & & & htn & & 11.0 & & 6.8 \\
\hline $\mathrm{H}-\mathrm{H}$ & & 0.251 & 20 & hty & & 7.9 & & 4.1 \\
\hline & & & & htn & & 16.3 & & 8.8 \\
\hline & & & 30 & hty & & 12.7 & & 5.5 \\
\hline & & & & htn & & 7.9 & & 5.1 \\
\hline & & & 10 & hty & & 3.5 & & 2.7 \\
\hline & & & & htn & & 13.9 & & 7.1 \\
\hline I-I & & 0.124 & 20 & hty & & 7.9 & & 3.9 \\
\hline & & & & htn & & 20.1 & & 9.2 \\
\hline & & & 30 & hty & & 12.3 & & 5.3 \\
\hline
\end{tabular}

Note: Black fonts represent the theoretically unfeasible projects; Blue fonts represent the theoretically feasible projects; Green fonts represent the practical plan.

\subsection{Comparative Analysis of the In Situ Monitoring Results}

To verify the correctness of the simulations while ensuring the engineering safety, long-term, real-time monitoring was implemented over the deformation of slope, overlying road and surrounding rocks, and Figure 23 displays the specific locations of the monitoring points. At an excavation distance of $30 \mathrm{~m}$, a horizontal settlement monitoring line was arranged on the ground surface, which included 
10 monitoring points (completely corresponding to the line 1 of the numerical model). The monitoring point $\mathrm{P} 1$ was put on the outer slope surface of the tunnel sidewall directly below line 1 for monitoring the horizontal deformation of the slope. Points P2 and P4 were put on the left and right sidewalls of the tunnel, respectively, for monitoring the horizontal displacement of the sidewalls. Point P3 was put on the roof of tunnel. In the same way, a monitoring line (comprising 10 points in total) was arranged on line 2 in the numerical model, which corresponded to monitoring points P5-P8 at the slope and tunnel interior. Based on the simulation results, the critical area with the largest deformation was chosen as the monitoring point arrangement area such that the monitoring results were highly representative.

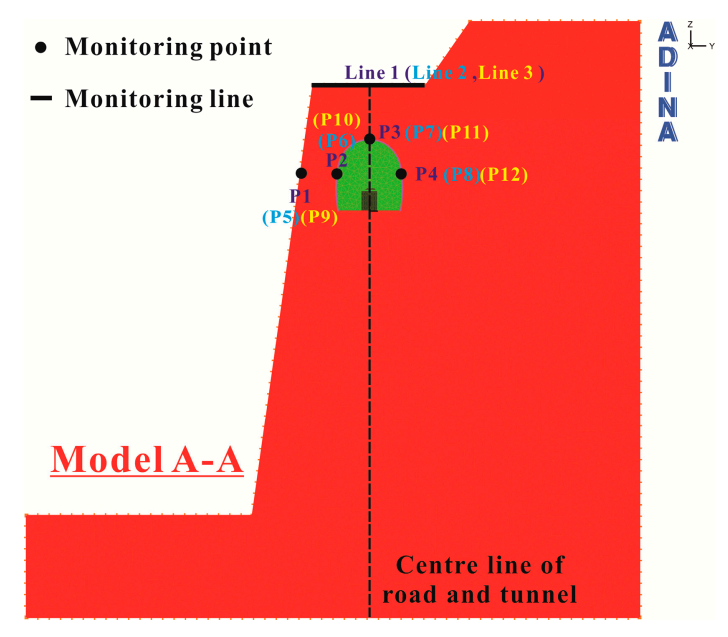

Figure 23. Schematic of in situ monitoring point locations.

The monitoring points for the deformation monitoring of the slope and surface settlements were already set up prior to the tunnel construction, while those for the deformation monitoring of the rocks surround the tunnel could only be set up as soon as possible after excavation of the tunnel. As the deformation curve of the whole process of the surrounding rock could not be obtained in the field, the displacement that was not monitored was also approximately reflected in the monitoring curve according to the excavation contour of surrounding rock.

Thus, Figure 24a shows rather complete monitoring data, whereas Figure $24 b-d$ only shows the relative displacements of the surrounding rocks following excavation. It is clear from Figure 24 that the critical stage affecting the deformation of slope and surrounding rocks was the approaching phase of the tunnel face [21]. All the monitored values were lower than the corresponding simulations, of which the slope stability deformation monitoring value was about $20 \%$ lower than the simulated value, and the final stability deformation monitoring values of the tunnel surrounding rocks were all lower than the upper limits $(15 \mathrm{~mm}$ and $20 \mathrm{~mm}$ ) for tunnel deformation stipulated by the Land Transport Authority (2000) and Building Department (2009) [9]. This indicates that the actual average mechanical parameters of the surrounding rocks were higher than those used in the simulation. Thus, the monitoring results not only proved the correctness of the simulation results, but also implied extra redundancy regarding the degree of engineering safety. 


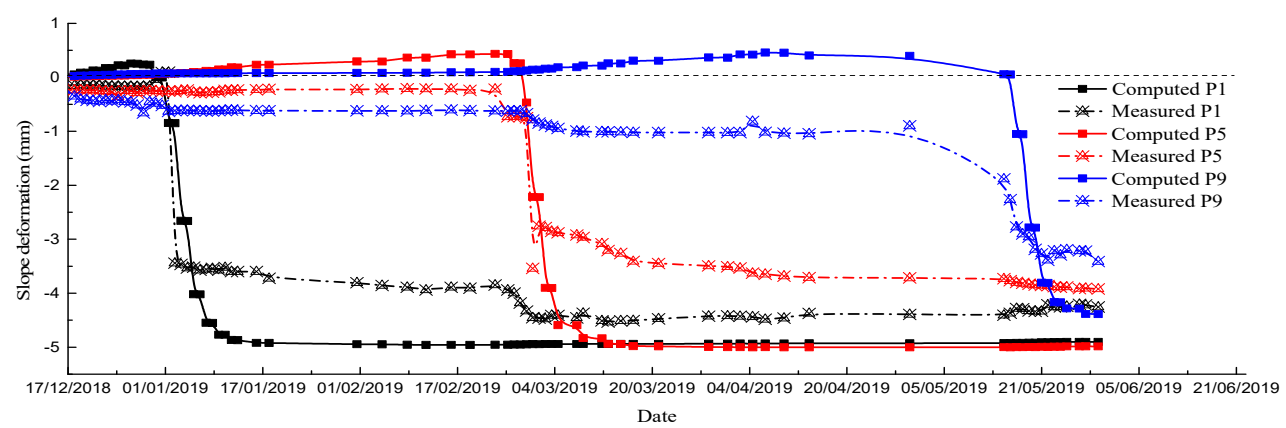

(a)

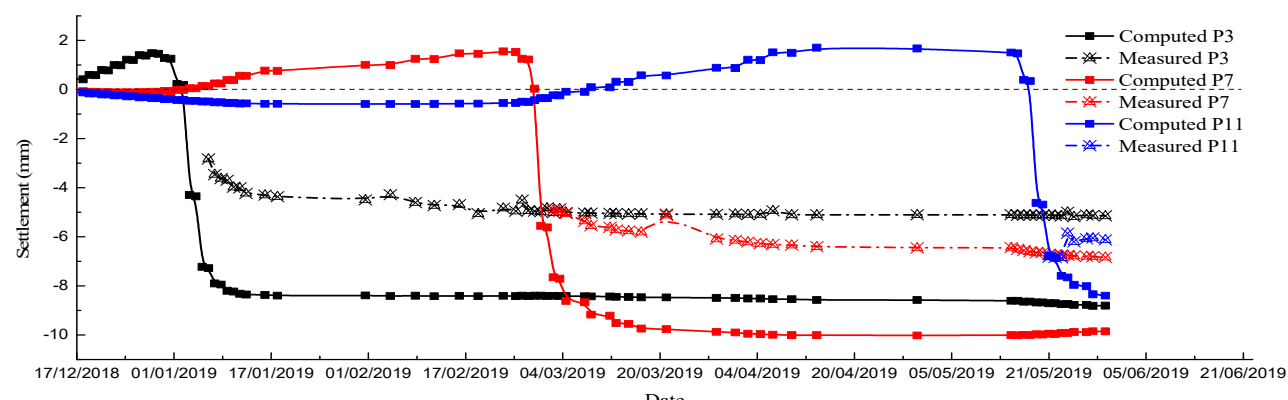

(b)

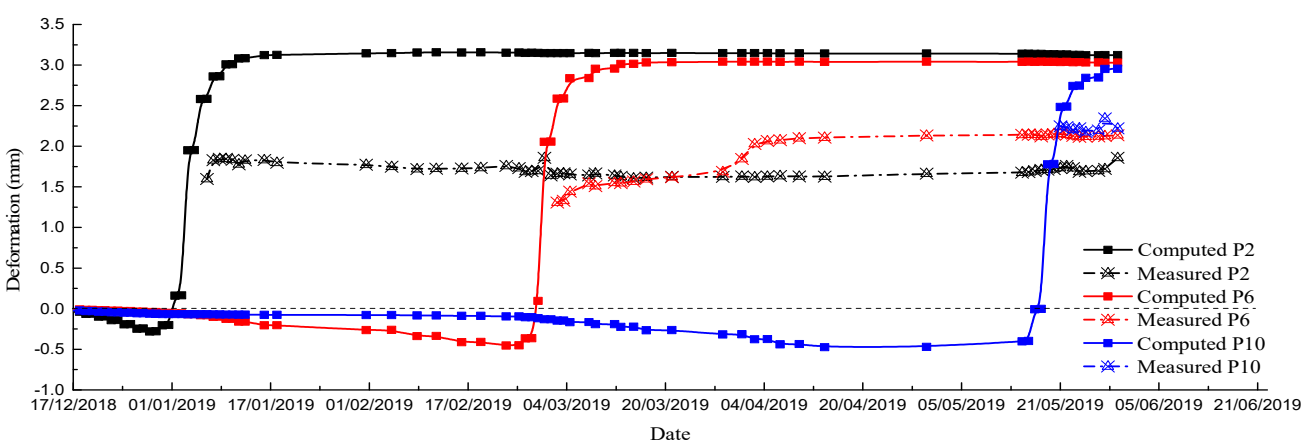

(c)

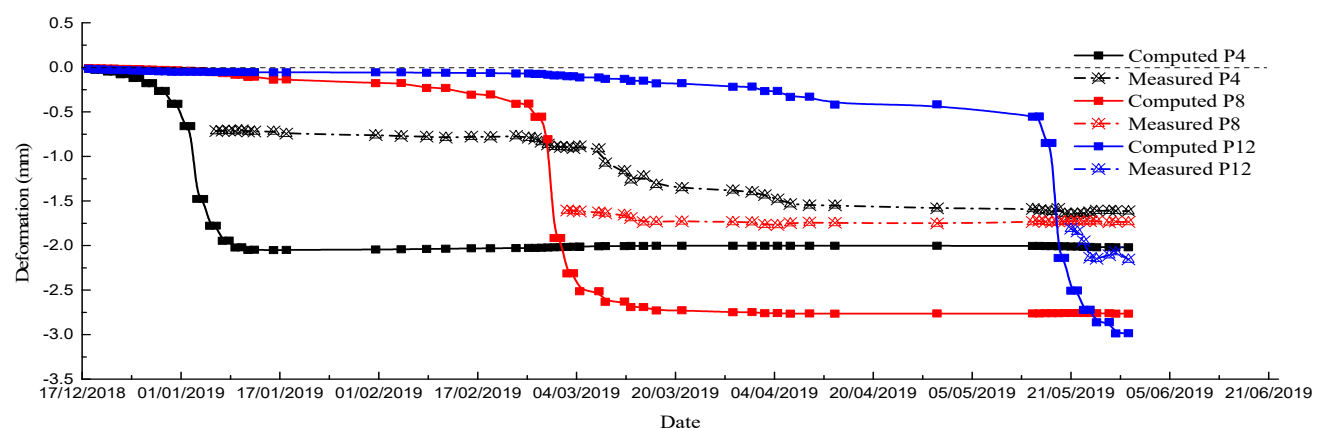

(d)

Figure 24. Deformation monitoring comparisons of the slope and the rocks surrounding the tunnel: (a) comparison of the time-history curves for the slope horizontal displacement, (b) comparison of the time-history curves for the tunnel vault vertical displacement, (c) comparison of the time-history curves for the tunnel left sidewall horizontal displacement, and (d) comparison of the time-history curves for the tunnel right sidewall horizontal displacement. 
In Figure 25, the horizontal settlement results of the ground surface are compared. As can be seen, the simulated settlement trough curves exhibited a symmetrical pattern since the surface load and new tunnel position were symmetrically distributed with respect to the road center in the numerical model. However, in the actual monitoring, the road surface conditions in the north side lane of the overlying road were poor since it had long been in disrepair, so all the vehicles chose to travel in the south lane where allowed (in China, vehicles are driven on the right side, and the right lane stretches along the right side of the excavation direction). As a result, a certain degree of bias was present in the actual surface load, which led to an asymmetrical shape of the monitoring curves, with the south-side monitoring values being slightly higher than the simulated values. Nevertheless, the overall trends were basically coincident, and the final maximum settlement fully satisfied the construction control requirements.

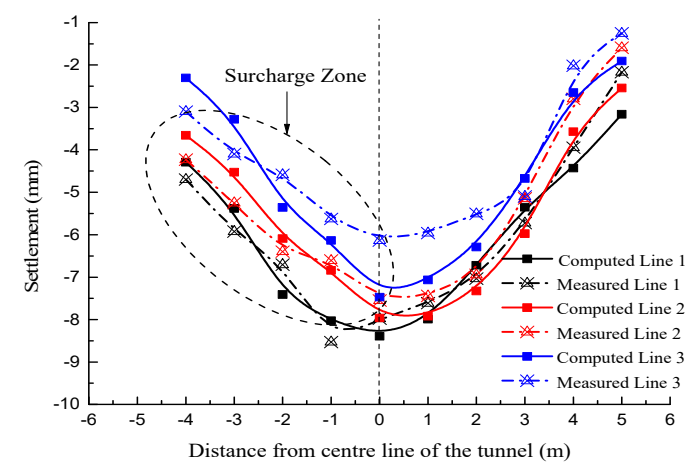

Figure 25. Comparison of final road settlement monitoring results.

\section{Conclusions}

(1) When parallel to the tunneling direction, the simulations revealed that a critical interval length must exist between the two tunnel lines such that the longitudinal surface settlement and slope deformation were significantly affected by the existing tunnel backfill. In this study, the area below the critical interval length was referred to as the longitudinal sensitive zone, within which the existing tunnel backfill had a positive effect on reducing the surface settlement. In the present case, the effect of the existing tunnel backfill began to weaken and even disappear after the split distance of two tunnel lines was longer than $2.5 \mathrm{~m}$. To save on project costs, the existing tunnel caverns in this zone may not be backfilled.

(2) Within the longitudinal sensitive zone perpendicular to the tunneling direction, the surface deformation presented a basically increasing trend with the decreases of the $\mathrm{C} / \mathrm{H}$ and $\mathrm{D} / \mathrm{W}$ ratios. When the specific value between the two ratios exceeded 5.2, an opposite trend of intensified surface settlement with an existing tunnel backfill will occur. An example is model $\mathrm{C}-\mathrm{C}(\mathrm{C} / \mathrm{H}=0.764$ and $\mathrm{D} / \mathrm{W}=0.16$ ) in the case studied herein. Meanwhile, the simulations revealed that the changes in the equivalent span and burial depth of the two tunnels were essentially attributed to the existing tunnel backfill and the positional variations of the tunnels. This, in turn, affected the shape of the surface settlement trough. When the geometric outline of an existing tunnel with a smaller cross section was contained completely by a larger tunnel, the location of the maximum horizontal surface settlement was controlled jointly by the spatial positions of the two tunnels. After a decrease of the geometric outline overlap zone in the increasing direction of the burial depth, the maximum horizontal surface settlement was controlled primarily by the tunnel with a larger cross section.

(3) Based on a comprehensive consideration of the upper limit criteria for the surface and slope deformations, model A-A ("hty" condition) was identified as the only feasible model among all models. Finally, the simulations of model A-A were compared with the monitored outcomes. As the results show, the tunnel face approaching phase was a decisive stage that affected the deformation of the surrounding rocks and slopes. Due to changes in the surface loads, the monitored outcomes 
of the horizontal surface settlement differed slightly from the simulations in the distribution pattern. Nevertheless, overall, the final maximum settlement completely complied with the construction control requirements. This not only proved the validity of the simulation results, but also suggested an additional redundancy for the degree of project safety.

Author Contributions: Conceptualization, Z.H. and C.L.; methodology, Z.H.; software, C.L.; formal analysis, Z.H.; data curation, Z.H.; writing—original draft preparation, Z.H. and C.L.; writing-review and editing, J.C.; supervision, Y.L.; project administration, Q.H.; funding acquisition, J.C. All authors have read and agreed to the published version of the manuscript.

Funding: This research was funded by the Key Program of National Natural Science Foundation of China (51638002).

Conflicts of Interest: The authors declare no conflict of interest.

\section{References}

1. Beyabanaki, A.R.; Gall, V. 3D numerical parametric study of the influence of open-pit mining sequence on existing tunnels. Int. J. Min. Sci. Technol. 2017, 27, 459-466. [CrossRef]

2. Bilotta, E.; Paolillo, A.; Russo, G.; Aversa, S. Displacements induced by tunnelling under a historical building. Tunn. Undergr. Space Technol. 2017, 61, 221-232. [CrossRef]

3. Chakeri, H.; Ozcelik, Y.; Unver, B. Effects of important factors on surface settlement prediction for metro tunnel excavated by EPB. Tunn. Undergr. Space Technol. 2013, 36, 14-23. [CrossRef]

4. Chen, R.; Lin, X.; Kang, X.; Zhong, Z.; Liu, Y.; Zhang, P.; Wu, H. Deformation and stress characteristics of existing twin tunnels induced by close-distance EPBS under-crossing. Tunn. Undergr. Space Technol. 2018, 82, 468-481. [CrossRef]

5. Dindarloo, S.R.; Siami-Irdemoosa, E. Maximum surface settlement based classification of shallow tunnels in soft ground. Tunn. Undergr. Space Technol. 2015, 49, 320-327. [CrossRef]

6. Fang, Q.; Tai, Q.; Zhang, D.; Wong, L.N.Y. Ground surface settlements due to construction of closely-spaced twin tunnels with different geometric arrangements. Tunn. Undergr. Space Technol. 2016, 51, 144-151. [CrossRef]

7. Gui, M.; Chen, S. Estimation of transverse ground surface settlement induced by DOT shield tunneling. Tunn. Undergr. Space Technol. 2013, 33, 119-130. [CrossRef]

8. Jin, D.; Yuan, D.; Li, X.; Zheng, H. An in-tunnel grouting protection method for excavating twin tunnels beneath an existing tunnel. Tunn. Undergr. Space Technol. 2018, 71, 27-35. [CrossRef]

9. Jin, D.; Yuan, D.; Li, X.; Zheng, H. Analysis of the settlement of an existing tunnel induced by shield tunneling underneath. Tunn. Undergr. Space Technol. 2018, 81, 209-220. [CrossRef]

10. Li, C.; Zhong, Z.; He, G.; Liu, X. Response of the ground and adjacent end-bearing piles due to side-by-side twin tunnelling in compound rock strata. Tunn. Undergr. Space Technol. 2019, 89, 91-108. [CrossRef]

11. Liang, R.; Xia, T.; Hong, Y.; Yu, F. Effects of above-crossing tunnelling on the existing shield tunnels. Tunn. Undergr. Space Technol. 2016, 58, 159-176. [CrossRef]

12. Lin, X.; Chen, R.; Wu, H.; Cheng, H. Deformation behaviors of existing tunnels caused by shield tunneling undercrossing with oblique angle. Tunn. Undergr. Space Technol. 2019, 89, 78-90. [CrossRef]

13. Mirhabibi, A.; Soroush, A. Effects of surface buildings on twin tunnelling-induced ground settlements. Tunn. Undergr. Space Technol. 2012, 29, 40-51. [CrossRef]

14. Ng, C.W.W.; Fong, K.Y.; Liu, H.L. The effects of existing horseshoe-shaped tunnel sizes on circular crossing tunnel interactions: Three-dimensional numerical analyses. Tunn. Undergr. Space Technol. 2018, 77, 68-79. [CrossRef]

15. Shi, J.; Fu, Z.; Guo, W. Investigation of geometric effects on three-dimensional tunnel deformation mechanisms due to basement excavation. Comput. Geotech. 2019, 106, 108-116. [CrossRef]

16. Shi, J.; Ng, C.W.W.; Chen, Y. A simplified method to estimate three-dimensional tunnel responses to basement excavation. Tunn. Undergr. Space Technol. 2017, 62, 53-63. [CrossRef]

17. Soomro, M.A.; Ng, C.W.W.; Liu, K.; Memon, N.A. Pile responses to side-by-side twin tunnelling in stiff clay: Effects of different tunnel depths relative to pile. Comput. Geotech. 2017, 84, 101-116. [CrossRef]

18. Vinod, M.; Khabbaz, H. Comparison of rectangular and circular bored twin tunnels in weak ground. Undergr. Space 2019, 4, 328-339. [CrossRef] 
19. Yang, J.; Liu, C.; Chen, Q.; Xie, X. Performance of overlapped shield tunneling through an integrated physical model tests, numerical simulations and real-time field monitoring. Undergr. Space 2017, 2, 45-59. [CrossRef]

20. Yin, M.; Jiang, H.; Jiang, Y.; Sun, Z.; Wu, Q. Effect of the excavation clearance of an under-crossing shield tunnel on existing shield tunnels. Tunn. Undergr. Space Technol. 2018, 78, 245-258. [CrossRef]

21. Zhang, C.; Zhang, X.; Fang, Q. Behaviors of existing twin subway tunnels due to new subway station excavation below in close vicinity. Tunn. Undergr. Space Technol. 2018, 81, 121-128. [CrossRef]

(C) 2020 by the authors. Licensee MDPI, Basel, Switzerland. This article is an open access article distributed under the terms and conditions of the Creative Commons Attribution (CC BY) license (http://creativecommons.org/licenses/by/4.0/). 